\title{
Genome-wide analyses of 200,453 individuals yields new insights into the causes and consequences of clonal hematopoiesis
}

\author{
Siddhartha P. Karr, ${ }^{1,2 *}$, Pedro M. Quiros ${ }^{3,4,5 *}+$, Muxin Gu ${ }^{3,4}$, Tao Jiang ${ }^{6}$, Ryan Langdon ${ }^{1,2}$, Vivek Iyer ${ }^{4}$, \\ Clea Barcena ${ }^{3,4}$, M.S. Vijayabaskar ${ }^{3,4}$, Margarete A. Fabre ${ }^{3,4,7}$, Paul Carter ${ }^{8}$, Stephen Burgess ${ }^{6,9}$, and \\ George S. Vassiliou $3,4,7 \dagger$
}

1. MRC Integrative Epidemiology Unit, University of Bristol, Bristol, BS8 2BN, United Kingdom.

2. Section of Translational Epidemiology, Division of Population Health Sciences, Bristol Medical School, University of Bristol, Bristol, BS8 2BN, United Kingdom.

3. Wellcome-MRC Cambridge Stem Cell Institute, University of Cambridge, Jeffrey Cheah Biomedical Centre, Cambridge, CB2 OAW, United Kingdom.

4. Wellcome Sanger Institute, Wellcome Genome Campus, Hinxton, Cambridge, CB10 1SA, United Kingdom.

5. Instituto de Investigación Sanitaria del Principado de Asturias, ISPA, 33011, Oviedo, Spain.

6. MRC/BHF Cardiovascular Epidemiology Unit, Department of Public Health and Primary Care, University of Cambridge, Strangeways Research Laboratory, Cambridge, CB1 8RN, United Kingdom.

7. Department of Haematology, Cambridge University Hospitals NHS Foundation Trust, Cambridge, CB2 0QQ, United Kingdom.

8. Division of Cardiovascular Medicine, Department of Medicine, Cambridge University Hospitals NHS Foundation Trust, Cambridge, CB2 0QQ, United Kingdom.

9. MRC Biostatistics Unit, University of Cambridge, Cambridge, CB2 OSR, United Kingdom.

* These authors contributed equally to this work.

† Correspondence: gsv20@cam.ac.uk ; siddhartha.kar@bristol.ac.uk ; pmquiros@ispasturias.es

\section{Abstract}

Clonal hematopoiesis $(\mathrm{CH})$ is one of the most extensively studied somatic mutational phenomena, yet its causes and consequences remain poorly understood. We identify 10,924 individuals with $\mathrm{CH}$ amongst 200,453 whole-exome sequenced UK Biobank participants and use their linked genomewide DNA genotypes to map the landscape of inherited predisposition to $\mathrm{CH}$. We increase the number of European-ancestry genome-wide significant $\left(P<5 \times 10^{-8}\right)$ germline associations with $\mathrm{CH}$ from four to 14 and identify one new transcriptome-wide significant $\left(P<3.2 \times 10^{-6}\right)$ association. Genes at new loci implicate DNA damage repair (PARP1, ATM, and CHEK2), hematopoietic stem cell migration/homing (CD164), and myeloid oncogenesis (SETBP1) in CH development. Several associations were $\mathrm{CH}$-subtype specific and, strikingly, variants at TCL1A and CD164 had opposite associations with DNMT3A- versus TET2-mutant $\mathrm{CH}$, mirroring recently reported differences in lifelong behavior of these two most common $\mathrm{CH}$ subtypes and proposing important roles for these loci in $\mathrm{CH}$ pathogenesis. Using Mendelian randomization, we show, amongst other findings, that smoking and longer leukocyte telomere length are causal risk factors for $\mathrm{CH}$ and demonstrate that genetic predisposition to $\mathrm{CH}$ increases risks of myeloproliferative neoplasia, several nonhematological malignancies, atrial fibrillation, and blood epigenetic age acceleration. 
medRxiv preprint doi: https://doi.org/10.1101/2022.01.06.22268846; this version posted January 6 , 2022. The copyright holder for this preprint (which was not certified by peer review) is the author/funder, who has granted medRxiv a license to display the preprint in

It is made available under a CC-BY-NC-ND 4.0 International license.

\section{Introduction}

The pervasive effects of ageing and somatic mutation shape the landscape of human disease in later life $^{1}$. A ubiquitous feature of ageing is the development of somatic mutation-driven clonal expansions in aged tissues ${ }^{2,3}$. In blood, somatic mutations that enhance cellular fitness of individual hematopoietic stem cells (HSCs) and their progeny, give rise to the common age-related phenomenon of clonal hematopoiesis $(\mathrm{CH})^{4-7}$. $\mathrm{CH}$ becomes increasingly prevalent with advancing age ${ }^{4-6}$ and is associated with an increased risk of hematological cancers ${ }^{4,5,8,9}$ and of some non-hematological conditions $s^{5,10,11}$. However, our understanding of the biological basis for these associations remains limited, as does our ability to explain how $\mathrm{CH}$ driver mutations promote clonal expansion of mutant $\mathrm{HSCs}^{12}$. In fact, whilst $\mathrm{CH}$ is defined by its association with somatic mutations, its development is influenced by nonmutation factors ${ }^{13-16}$ and by the heritable genome ${ }^{17,18}$, in ways that remain poorly understood.

Insights into the causes and consequences of $\mathrm{CH}$ are confounded by its intimate relationship with ageing. Moreover, even when robust associations are identified, their causality can be difficult to establish. Here, we perform a comprehensive investigation of the genetic and phenotypic associations of $\mathrm{CH}$ in 200,453 United Kingdom Biobank (UKB) participants, yielding a step change in our understanding of $\mathrm{CH}$ pathogenesis. Our study reveals multiple new germline loci associated with $\mathrm{CH}$, including several that interact with specific $\mathrm{CH}$ subtypes, uncovers causal links between $\mathrm{CH}$ and diverse pathological states across organ systems, and provides evidence for causal associations between smoking and telomere length and $\mathrm{CH}$ risk, amongst a series of novel insights.

\section{Results}

\section{Prevalence of $\mathrm{CH}$ and its distribution by age and sex in the UKB}

To identify individuals with $\mathrm{CH}$, we analyzed blood whole exome sequencing (WES) data from 200,453 UKB participants ${ }^{19}$ aged 38-72 years (Extended Data Fig. 1a-c). We called somatic mutations in $43 \mathrm{CH}$ genes (Supplementary Table 1) and filtered these against a predefined list of $\mathrm{CH}$ driver variants (Supplementary Tables 2 and 3). This identified 11,697 mutations (Supplementary Table 4) in 10,924 individuals (UKB prevalence: 5.45\%). DNMT3A, TET2, and ASXL1 were most commonly involved (79\% of all mutations), followed by mutations in DNA damage response genes PPM1D, TP53, and ATM; splicing factor genes SRSF2 and SF3B1; JAK2 and GNB1 (Fig. 1a), in line with previous reports ${ }^{4,5,17}$. Most $\mathrm{CH}$ carriers $(n=10,228)$ harbored one and some $(n=696) 2-4$ mutations; most of which were missense variants dominated by cytosine-to-thymine (C>T) transitions (Extended Data Fig. 1d-f). The mean variant allele fraction (VAF) was 0.12 and VAF distribution did not differ between mutation types (Extended Data Fig. 1g and h). VAF distribution did differ between individual genes (Fig. 1a), although some of this variation was probably influenced by variation in sequencing depth (Supplementary Table 1).

$\mathrm{CH}$ prevalence rose progressively with age $\left(P<10^{-300} ; \mathrm{Fig} .1 \mathrm{~b}\right)$, as did clone size measured by VAF $\left(P=8.2 \times 10^{-37}\right.$; Extended Data Fig. 2a). Females and males were similarly affected with similar median ages (Extended Data Fig. 2b). The age-related rise in prevalence differed between drivers: compared to DNMT3A, mutations in ATM were observed earlier and those in ASXL1, PPM1D, SF3B1, and SRSF2 were observed later (Extended Data Fig. 2c). Furthermore, we noted significant differences in the prevalence of different $\mathrm{CH}$ gene mutations between sexes, with GNB1 and DNMT3A mutations more frequent in females and PPM1D, TP53, JAK2, SF3B1, ASXL1, and SRSF2 mutations more frequent in males (Fig. 1C), reflecting their relative prevalence in myeloid malignancies ${ }^{20}$. 
medRxiv preprint doi: https://doi.org/10.1101/2022.01.06.22268846; this version posted January 6 , 2022. The copyright holder for this preprint (which was not certified by peer review) is the author/funder, who has granted medRxiv a license to display the preprint in

It is made available under a CC-BY-NC-ND 4.0 International license.

\section{Associations between $\mathrm{CH}$ and traits/diseases prevalent at the time of blood sampling}

To identify associations between $\mathrm{CH}$ and traits or diseases prevalent at the time of enrolment to the UKB, we performed regression analyses adjusting for age, sex, smoking status, WES batch and the first ten genetic ancestry principal components. Individuals with $\mathrm{CH}$ showed higher average platelet, leukocyte, reticulocyte, and neutrophil counts and red blood cell distribution width (RDW), but lower eosinophil counts (Fig. 2a). These associations were more pronounced in individuals with large $\mathrm{CH}$ clones (VAF $\geq 0.1$; Fig. 2a; Supplementary Table 5). JAK2-driven $\mathrm{CH}$ was associated with markedly higher platelet counts, RDW and hemoglobin/hematocrit (HGB/HT) levels. In contrast, splicing factor-mutant $\mathrm{CH}$ was associated with lower HGB/HT and higher mean red cell volume (MCV; Fig. 2a; Supplementary Table 5). We also found that $\mathrm{CH}$ status was associated with lower levels of total and low-density lipoprotein cholesterol (Fig. 2b; Supplementary Table 6). Advancing age increased the risk of $\mathrm{CH}$ by 6.7\% per year (OR=1.07, 95\% $\mathrm{Cl}: 1.06-1.07, P<10^{-300}$; Fig. $2 \mathrm{c}$ ); and $\mathrm{CH}$ status was associated with increased prevalence of hypertension, but not obesity or type 2 diabetes (T2D; Fig. 2C; Supplementary Table 7). Also, individuals with $\mathrm{CH}$ were more likely to be current, past, or "ever" smokers, an association that held true for different forms of $\mathrm{CH}$ and was strongest for ASXL1-mutant $\mathrm{CH}$ (Fig 2c and 2d; Supplementary Table 7).

\section{Associations between $\mathrm{CH}$ and incident disease}

We next investigated relationships between $\mathrm{CH}$ at baseline and traits/diseases that developed subsequently (Supplementary Table 8) and identified strong associations with incident myeloid malignancies (MM) and associated sequelae (Extended Data Fig. 3a and Supplementary Table 9). The association was strong for all MM subtypes and highest for chronic myelomonocytic leukemia (CMML; Fig. 2e), whilst large clone $\mathrm{CH}$ increased the risk of MMs three-to-five-fold compared to small clone $\mathrm{CH}$ (VAF<0.1; Extended Data Fig. 3b; Supplementary Table 10). SF3B1 and SRSF2 mutations conferred very high risks of CMML and myelodysplastic syndromes (Extended Data Fig. 3c; Supplementary Table 10). CH was also associated with increased risks of Hodgkin's and non-Hodgkin's lymphomas and nonhematological neoplasia, including lung, head and neck, kidney, bladder, colorectal, and stomach cancers (Fig. 2f; Supplementary Table 11). The association of $\mathrm{CH}$ with lung adenocarcinoma was consistently observed across large and small clones, and with DNMT3A and ASXL1 mutations, whilst the association with overall $\mathrm{CH}$ persisted in self-reported never-smokers (Extended Data Fig. $3 \mathrm{~d}$ ).

As $\mathrm{CH}$ was previously identified as a risk factor for ischemic cardiovascular disease $(C V D)^{5,10,21}$, we examined the association in this much larger cohort (Fig. 2g; Supplementary Table 12). Using multivariable models, we did not find a significant association between $\mathrm{CH}$ and ischemic CVD, including coronary artery disease (CAD) and stroke; however, we did find significantly increased risks of heart failure and a composite of all CVD conditions (Fig. 2g; Supplementary Table 12). Using a bivariable model including age as the only other covariate, we also found a significant association with atrial fibrillation, with an effect size estimate consistent with that in multivariable analysis (Extended Data Fig. 3e; Supplementary Table 12). Our multivariable analyses also found significant associations between $\mathrm{CH}$ and increased risk of death from any cause, malignant neoplasm, and hematological neoplasm, whilst large clone $\mathrm{CH}$ was also associated with an increased risk of death due to the composite of CVDs (Fig. 2h; Supplementary Table 13).

\section{Heritability and cell type-specific enrichment of polygenic susceptibility to $\mathrm{CH}$}

To identify heritable determinants of $\mathrm{CH}$ risk, we performed a genome-wide association study (GWAS) on the 184,121 individuals with genetically inferred European ancestry to identify common (minor allele frequency (MAF)>1\%) germline genetic variants predisposing to $\mathrm{CH}$. In the GWAS, we compared 10,203 individuals with $\mathrm{CH}$ with 173,918 individuals without $\mathrm{CH}$, after quality control of the germline 
medRxiv preprint doi: https://doi.org/10.1101/2022.01.06.22268846; this version posted January 6, 2022. The copyright holder for this preprint (which was not certified by peer review) is the author/funder, who has granted medRxiv a license to display the preprint in

It is made available under a CC-BY-NC-ND 4.0 International license.

genotype data. Linkage disequilibrium score regression (LDSC) ${ }^{22}$ showed little evidence of inflation in test statistics due to population structure, with an intercept of 1.009 and lambda genomic control factor of 0.999 . The narrow-sense (additive) heritability of $\mathrm{CH}$ was estimated at $3.57 \%$ (s.e. $=0.85 \%$ ). We partitioned the heritability of $\mathrm{CH}$ across four major histone marks observed in 10 cell type groups aggregated from 220 cell-type specific annotation ${ }^{23}$ and identified strong enrichment of the polygenic $\mathrm{CH}$ association signal in histone marks enriched in hematopoietic cells $\left(P=5.9 \times 10^{-5}\right.$; Fig. 3a; Supplementary Table 14). Next, we partitioned the heritability of $\mathrm{CH}$ across open chromatin state regions in various hematopoietic progenitor cells and lineages ${ }^{23,24}$. We found evidence of $\mathrm{CH}$ heritability enrichment in accessible chromatin regions in HSCs, common lymphoid and myeloid progenitors, multipotent and erythroid progenitors, and B cells (Fig. 3b; Supplementary Table 15). Overall, these findings are in keeping with the intuitive assumption that the $\mathrm{CH}$ GWAS exerts its greatest biological effect on $\mathrm{HSC} /$ progenitor populations.

\section{Germline genetic loci associated with overall $\mathrm{CH}$ susceptibility}

Linkage disequilibrium (LD)-based clumping of 9,715,652 common variants identified seven independent $\left(r^{2}<0.05\right)$ genome-wide significant loci (lead variant $\left.P<5 \times 10^{-8}\right)$ associated with risk of developing $\mathrm{CH}$, including three previously reported ${ }^{17}$ European-ancestry $\mathrm{CH}$ loci: two at $5 \mathrm{p} 15.33$-TERT and one at 3q25.33-SMC4 (Fig. 4a; Supplementary Table 16). We identified a new top variant in the 5 p15.33 region, rs $2853677\left(P=2.4 \times 10^{-50}\right)$, which was weakly correlated $\left(r^{2}=0.19\right)$ with the previously reported ${ }^{17}$ top variant, $r s 7705526\left(P=3.4 \times 10^{-44}\right.$ in our analysis). Overall, there was evidence for three independent $\left(r^{2}<0.05\right)$ signals at $5 p 15.33$ marked by lead variants $r 2853677$, rs13156167, and rs2086132, the latter representing a new signal independent of the two previously published ${ }^{17}$ signals rs7705526 and rs13167280. After approximate conditional analysis ${ }^{25}$ (Supplementary Table 17) conditioning on the three lead variants in the TERT region, the previously published top variant, rs7705526, continued to remain genome-wide significant suggesting that it represented a fourth signal in this region. Conditional analysis also highlighted the existence of a fifth independent association at 5p15.33 marked by $\mathrm{rs} 13356700 \sim 776 \mathrm{~kb}$ from TERT and $\sim 34 \mathrm{~kb}$ from EXOC3 (Supplementary Table 17) that encodes an exocyst complex component implicated in arterial thrombosis ${ }^{26}$. The variant $r s 13356700$ was in strong LD $\left(r^{2}=0.84\right)$ with $r s 10072668$ that is associated with $\mathrm{HGB} / \mathrm{HT}^{27}$. At $3 \mathrm{q} 25.33-\mathrm{SMC4}$, the previously reported ${ }^{17}$ top variant, $\mathrm{rs} 1210060191$, was not captured in the UKB and our top association was rs12632224 $\left(P=2.3 \times 10^{-9}\right)$. We also identified three other novel genome-wide significant loci associated with overall $\mathrm{CH}$ susceptibility (Fig. 4a; Supplementary Table 16): 4q35.1-ENPP6 (rs13130545), 6q21-CD164 (rs35452836), and 11q22.3-ATM (rs11212666).

\section{CH GWAS stratified by gene and clone size, association heterogeneity, and rare variant associations}

Next, we investigated whether the development of certain $\mathrm{CH}$ subtypes may be affected by germline variants. Thus, we performed GWAS for four additional $\mathrm{CH}$ traits - stratifying by the two main mutated genes in $\mathrm{CH}, D N M T 3 A$ and TET2, and by clonal size, differentiating large and small clones. Focusing on 5,185 individuals with DNMT3A and 2,041 with TET2 mutations and using the 173,918 individuals of European ancestry without detectable $\mathrm{CH}$ as controls, we identified eight and three genome-wide significant loci associated with DNMT3A- and TET2-mutant $\mathrm{CH}$, respectively (Figs. $4 \mathrm{~b}$ and $4 \mathrm{c}$; Supplementary Tables 18 and 19). We replicated the only previously published European-ancestry $\mathrm{CH}$ risk locus associated with DNMT3A-CH at 14q32.13-TCL1A. The overall CH loci at 5p15.33-TERT (signals with lead variants rs2853677, rs13156167, and rs7705526), 3q25.33-SMC4, 6q21-CD164, and 11q22.3-ATM were also genome-wide significant for DNMT3A-mutant $\mathrm{CH}$. We also found two novel loci for DNMT3A-CH marked by lead variants rs138994074 at 1q42.12-PARP1 and rs8088824 at 18q12.3-SETBP1 (Fig. 4b; Supplementary Table 18). The three TET2-CH associated loci included the lead variant rs 2736100 at $5 \mathrm{p} 15.33-\mathrm{TERT}$, that was moderately correlated $\left(r^{2}=0.44\right)$ with the overall $\mathrm{CH}$ 
medRxiv preprint doi: https://doi.org/10.1101/2022.01.06.22268846; this version posted January 6 , 2022. The copyright holder for this preprint (which was not certified by peer review) is the author/funder, who has granted medRxiv a license to display the preprint in

It is made available under a CC-BY-NC-ND 4.0 International license.

lead variant rs2853677 in the same region. The other two risk loci, both new in the context of TET2$\mathrm{CH}$, were at lead variants rs10131341 (14q32.13-TCL1A) and rs79633204 (7q32.2-TMEM209; Fig. 4c; Supplementary Table 19). Notably, the A allele of rs10131341 had opposite associations with TET2-CH (OR=1.28, $\left.P=6.8 \times 10^{-10}\right)$ versus DNMT3A-CH $\left(\mathrm{OR}=0.87, P=6.4 \times 10^{-8}\right)$. A trend for opposite effects at 14q32.13-TCL1A was also observed in a previous study ${ }^{17}$, but did not achieve genome-wide significance for TET2-CH.

When comparing 4,049 individuals with large or 6,154 individuals with small clones against 173,918 controls of European ancestry without $\mathrm{CH}$, we found that the overall $\mathrm{CH}$ loci at $5 \mathrm{p} 15.33-T E R T$ and 3q25.33-SMC4 were associated at genome-wide significance with large clone $\mathrm{CH}$ (Fig. 4d; Supplementary Table 20), while 5p15.33-TERT and 6q21-CD164 were associated with small clone $\mathrm{CH}$. For small clone $\mathrm{CH}$ risk, we also identified a previously unreported locus marked by rs72755524 at 5 p13.3 in a region with several lincRNAs (Fig. 4e; Supplementary Table 21). Additional signals suggested by approximate conditional analysis at each locus identified in this study are listed in Supplementary Table 17. Examining heterogeneity of associations across the five $\mathrm{CH}$ traits using forest plots (Extended Data Fig. 4) revealed that in addition to 14q32.13-TCL1A, the lead alleles at 6q21CD164 also had opposite effects on DNMT3A- versus TET2-CH. In addition, the lead variants at 6q21CD164 and 5p13.3-LINCO2064 were associated with small, but not large, clones while the association at 7q32.2-TMEM209 was highly specific to TET2-CH.

Finally, in addition to our common variant GWAS, we performed a more focused scan to explore rare variant (MAF: $0.2 \%-1 \%$ ) associations in each of three $\mathrm{CH}$ traits that included $>5,000$ European-ancestry individuals with $\mathrm{CH}$ (i.e., overall $\mathrm{CH}, D N M T 3 A-\mathrm{CH}$, and small clone $\mathrm{CH}$; each compared to 173,918 controls) declaring associations significant at $P<10^{-9}$. This identified one new locus at 22q12.1-CHEK2 where the T allele (frequency $=0.3 \%$ ) of lead variant $r 562237617$ was perfectly correlated $\left(r^{2}=1\right)$ with the 1100 delC CHEK2 protein-truncating allele ( $r 555607708)$ and conferred a large increase in risk of DNMT3A mutation-associated $\mathrm{CH}\left(\mathrm{OR}=4.1,95 \% \mathrm{Cl}\right.$ : 2.7-6.1, $\left.P=6.3 \times 10^{-12}\right)$. The CHEK2 c.1100delC frameshift mutation or its tagging variant rs62237617 are known to be associated with myeloproliferative neoplasms (MPNs) and JAK2 V617F-driven $\mathrm{CH}$ (though not genome-wide significant for either trait) ${ }^{18}$, elevated white blood cell counts and plateletcrit ${ }^{27}$, as well as risk of prostate and breast cancers ${ }^{28,29}$. The DNMT3A-CH risk increasing alleles in the CHEK2 and PARP1 regions were also associated with later age at menopause in a recent analysis ${ }^{30}$, suggesting a role for inhibition of DNA damage sensing and apoptosis in both $\mathrm{CH}$ and reproductive ageing ${ }^{31}$.

\section{Genetic relationship between hematological chromosomal mosaicism and $\mathrm{CH}$ due to gene mutation}

It is not known whether the germline genetic architecture underlying predisposition to $\mathrm{CH}$ due to individual gene mutations is similar to that underlying the risk of $\mathrm{CH}$ due to mosaic chromosomal alterations (mCAs). We used data from a recent GWAS of blood $m C A s^{32}$ to answer this question and found that 13 of 19 unique lead variants identified for the five gene-mutant $\mathrm{CH}$ traits (overall, DNMT3A, TET2-, and large and small clone $\mathrm{CH}$ ) were associated with hematological mCA risk at $P<10^{-}$ ${ }^{4}$ (Supplementary Table 22). Notably, for our lead variants rs2296312 (14q32.13-TCL1A) and rs8088824 (18q12.3-SETBP1), the alleles conferring increased DNMT3A-CH risk reduced hematological mCA risk (Supplementary Table 22). At the genome-wide level we found a correlation between overall $\mathrm{CH}$ and mCAs $\left(r_{\mathrm{g}}=0.44\right.$, s.e. $\left.=0.21, P=0.037\right)$ using $\operatorname{LDSC}^{22}$. Further, a phenome-wide $\operatorname{scan}^{33,34}$ showed that several newly identified lead variants in our analyses were associated with multiple blood cell counts and traits (Supplementary Table 23). 
medRxiv preprint doi: https://doi.org/10.1101/2022.01.06.22268846; this version posted January 6 , 2022. The copyright holder for this preprint (which was not certified by peer review) is the author/funder, who has granted medRxiv a license to display the preprint in

It is made available under a CC-BY-NC-ND 4.0 International license .

\section{Gene-level associations and network analyses}

We supplemented our GWAS with gene-level association tests for each of our five $\mathrm{CH}$ traits using two complementary methods: multi-marker analysis of genomic annotation (MAGMA) and a transcriptome-wide association study (TWAS) using blood-based cis gene expression quantitative trait locus data on 31,684 individuals ${ }^{35}$ and summary-based Mendelian randomization (SMR) coupled with the heterogeneity in dependent instruments colocalization test ${ }^{36}$. Both approaches converged on a new locus at 6p21.1, associated at gene-level genome-wide significance $\left(P_{\text {MAGMA }}<2.6 \times 10^{-6}\right.$, $\left.P_{\mathrm{SMR}}<3.2 \times 10^{-6}\right)$ with DNMT3A-mutant $\mathrm{CH}$ and marked by CRIP3 $\left(P_{\mathrm{MAGMA}}=3.4 \times 10^{-7}, P_{\mathrm{SMR}}=6.6 \times 10^{-7}\right.$; Fig. 3 a; Supplementary Tables 24 and 25). While CRIP3 is the only $6 \mathrm{p} 21.1$ gene to reach gene-level genomewide significance in both MAGMA and SMR, we did find sub-threshold evidence for association between SRF or ZNF318 in the same region and DNMT3A-mutant CH (Fig. 5a). Of note, SRF encodes the serum response factor that is known to regulate HSC adhesion ${ }^{37}$ while ZNF318 is an occasional somatic driver gene for $\mathrm{CH}^{38}$. More globally, protein-protein interaction (PPI) network analysis ${ }^{39}$ using proteins encoded by the 57 genes with $P_{\text {MAGMA }}<0.001$ in the overall $\mathrm{CH}$ analysis (Supplementary Table 24) as "seeds", identified the largest sub-network (Fig. 5b) as encompassing 13/57 proteins with major hub nodes highlighted as TERT, PARP1, ATM, and SMC4. This was consistent with the emerging theme that key genes at sub-threshold GWAS loci for the same trait are often part of interconnected biological networks ${ }^{40,41}$. The sub-threshold genes identified by MAGMA that encoded protein hubs in this network included FANCF (DNA repair pathway) and PTCH1 (hedgehog signaling; Fig. 5b), both implicated in the pathogenesis of acute myeloid leukemia ${ }^{42,43}$ and $G N A S$, a somatic driver of $\mathrm{CH}^{44}$. The $\mathrm{CH}$ sub-network (seeds and non-seed interacting proteins) was significantly enriched for several pathways of relevance to common disease including DNA repair, cell cycle regulation, telomere maintenance, and platelet homeostasis (Supplementary Table 26).

\section{Functional target gene prioritization at $\mathrm{CH}$ risk loci}

In order to prioritize putative functional target genes at the $P_{\text {lead-variant }}<5 \times 10^{-8}$ loci identified by our GWAS of five $\mathrm{CH}$ traits, we combined gene-level genome-wide significant results from MAGMA and SMR (Supplementary Tables 24 and 25) with five other lines of evidence: PPI network hub status of the gene (Supplementary Table 27), variant-to-gene searches of the Open Targets database ${ }^{45}$ for lead variants, overlap between fine-mapped variants ${ }^{46,47}$ (Supplementary Table 28) and (i) gene bodies, (ii) regions with accessible chromatin correlated with nearby gene expression in hematopoietic progenitor cells ${ }^{24,48-50}$, and (iii) missense variant annotations ${ }^{51,52}$ (Supplementary Table 29). Genes nominated by at least two of these approaches are listed in Fig. $5 \mathrm{c}$. The genes nominated by the largest number of approaches, and representing the most likely targets, were SMC4, ENPP6, TERT, CD164, ATM, PARP1, TCL1A, SETBP1, and TMEM209.

Among the newly identified loci, CD164 codes for Sialomucin core protein 24, a cell adhesion molecule that regulates HSC adhesion, proliferation, and migration ${ }^{53,54}$. Lead variant rs 138994074 at $1 \mathrm{q} 42.12$ was strongly correlated $\left(r^{2}=0.93\right)$ with $r(136410$, a missense germline mutation in PARP1 (Supplementary Table 29) wherein the $\mathrm{G}$ allele, which is protective for DNMT3A-CH, leads to a missense variant (p.Val762Ala) in the catalytic domain of its protein product associated with reduced Poly (ADP-ribose) polymerase-1 activity ${ }^{55}$. While SETBP1 was only nominated by one approach (Open Targets ${ }^{45}$ ) and was the only gene nominated at 18q12.3, its nomination is strengthened by the fact that somatic SETBP1 mutations are recognized drivers of myeloid malignancies ${ }^{56,57}$.

\section{Mendelian randomization (MR) to uncover the causes and consequences of $\mathrm{CH}$}

We integrated several large GWAS datasets (Supplementary Tables 30 and 31) and used two-sample inverse-variance-weighted $\mathrm{MR}^{58}$ to appraise putative causes and consequences of $\mathrm{CH}$. Genetically- 
medRxiv preprint doi: https://doi.org/10.1101/2022.01.06.22268846; this version posted January 6, 2022. The copyright holder for this preprint (which was not certified by peer review) is the author/funder, who has granted medRxiv a license to display the preprint in

It is made available under a CC-BY-NC-ND 4.0 International license .

307 predicted smoking initiation ${ }^{59}$ was associated with overall $\mathrm{CH}$ risk $(\mathrm{OR}=1.15,95 \% \mathrm{Cl}$ : $1.05-1.25$, $\left.308 P=2.2 \times 10^{-3}\right)$. Point estimates of the effect size were consistent in direction across MR analyses for 309 DNMT3A, TET2, and large and small clone CH (Fig. 6a; Supplementary Table 32), with the largest odds 310 ratio observed for large clone $\mathrm{CH}(\mathrm{OR}=1.24)$. We also appraised the roles of leukocyte telomere length $311(\mathrm{LTL})^{60}$, alcohol use ${ }^{59}$, adiposity ${ }^{61}$, genetic liability to $\mathrm{T}^{2} \mathrm{D}^{62}$, major circulating lipids ${ }^{63}$, blood-based 312 epigenetic aging phenotypes ${ }^{64}$, blood cell counts and indices ${ }^{27}$, and circulating cytokines and growth 313 factors ${ }^{65}$ as potential risk factors for $\mathrm{CH}$ using MR (Fig. 6; Supplementary Tables 32, 33, and 34 for full 314 results, including sensitivity analyses). Genetically predicted longer LTL was associated with increased overall $\mathrm{CH}$ risk $\left(\mathrm{OR}=1.56,95 \% \mathrm{Cl}: 1.25-1.93, P=5.7 \times 10^{-5}\right)$, an association that was also seen with DNMT3A-, TET2-, and large and small clone CH (Fig. 6b; Supplementary Table 32). We found that higher genetically predicted $\mathrm{BMI}$ was associated with increased risk of large clone $\mathrm{CH}(\mathrm{OR}=1.15,95 \% \mathrm{Cl}$ : 1.01-1.31, $P=0.029)$. Genetically elevated circulating apolipoprotein $B$ levels were associated with increased ( $O R=1.18,95 \% \mathrm{Cl}: 1.01-1.36, P=0.032$; Fig. $6 \mathrm{c}$ ), whilst genetically predicted alcohol use was associated with decreased (OR=0.46, $95 \% \mathrm{Cl}: 0.25-0.83, P=0.010)$ risk of $T E T 2-\mathrm{CH}$. Among cytokines, genetically-elevated circulating macrophage inflammatory protein $1 \mathrm{a}$, a regulator of myeloid differentiation and HSC numbers ${ }^{66}$, was associated with risk of DNMT3A-CH (OR=1.13, 95\% $\mathrm{Cl} 1.03-$ 1.23, $P=7.1 \times 10^{-3}$; Supplementary Table 34).

We used independent $\left(r^{2}<0.001\right)$ variants associated with overall, DNMT3A, TET2, and large and small clone $\mathrm{CH}$ at $P<10^{-5}$ as genetic instruments for each of these traits and assessed their associations with outcomes (Supplementary Tables 31, 35, and 36 for full results, including sensitivity analyses). Since more variants were available at $P<5 \times 10^{-8}$ for overall and for DNMT3A CH, we also examined the consistency of associations when using genome-wide (GWS; $P<5 \times 10^{-8}$ ) and sub-genome-wide significant (sub-GWS; $P<10^{-5}$ ) instruments for these two traits. Using the sub-GWS instrument, genetic liability to overall $\mathrm{CH}$ had the largest associations (Fig. 7a) with $\mathrm{MPN}$ risk ${ }^{48}(\mathrm{OR}=1.99,95 \% \mathrm{Cl}$ : 1.23-3.23, $P=5.4 \times 10^{-3}$ ), intrinsic epigenetic age acceleration ${ }^{64}$ (IEAA, which represents a core characteristic of $\mathrm{HSCs}^{67}$; beta $=0.39,95 \% \mathrm{Cl}: 0.08-0.69, P=0.01$ ) and the blood-based Hannum epigenetic clock $^{64}$ (beta= $0.27,95 \% \mathrm{Cl}: 0.04-0.49, P=0.02$ ). Larger associations were observed when using the GWS instrument (Fig. 7a) and the direction of these was consistent when evaluating genetic liability to DNMT3A, TET2, and large and small clone $\mathrm{CH}$ as exposures (Supplementary Tables 35 and 36). Genetic liability to $\mathrm{CH}$ conferred increased risks of lung ${ }^{68}$, prostate ${ }^{69}$, ovarian ${ }^{70}$, oral cavity/pharyngeal ${ }^{71}$, and endometrial cancers $^{72}$ (Fig. 7; Supplementary Table 35) with the strongest associations observed between overall $\mathrm{CH}$ and lung $\left(\mathrm{OR}=1.17,95 \% \mathrm{Cl}\right.$ : $\left.1.05-1.29, P=2.9 \times 10^{-3}\right) ; D N M T 3 A-\mathrm{CH}$ and prostate $(\mathrm{OR}=1.08,95 \% \mathrm{Cl}$ : 1.03-1.13, $\left.P=8.6 \times 10^{-4}\right)$, ovarian (OR=1.07, $\left.95 \% \mathrm{Cl}: 1.01-1.12, P=0.015\right)$, and oral cavity/pharyngeal (OR=1.24, 95\%Cl: 1.07-1.44, $\left.P=4.4 \times 10^{-3}\right)$; and TET2-CH and endometrial (OR=1.05, 95\%Cl: 1.00-1.09, $P=0.033$ ) cancers. MR analyses did not support causal risk-conferring associations between genetic liability to $\mathrm{CH}$ and $\mathrm{CAD}^{73}$, ischemic stroke ${ }^{74}$, and heart failure ${ }^{75}$ with similar lack of evidence across gene-specific and clone size-specific $\mathrm{CH}$, and GWS instrument analyses (Fig. 7; Supplementary Table 35). However, we did uncover an association between genetic liability to overall $\mathrm{CH}$ or DNMT3A-CH and atrial fibrillation ${ }^{76}$ risk $\left(\mathrm{OR}=1.09,95 \% \mathrm{Cl}\right.$ : $1.04-1.15, P=4.9 \times 10^{-4}$ for overall $\mathrm{CH}$ with the GWS instrument; Supplementary Table 35). Among cytokines and growth factors ${ }^{65}$, genetic liability to overall $\mathrm{CH}$ was associated with elevated circulating stem cell growth factor beta (beta $=0.19 ; 95 \% \mathrm{Cl}$ : 0.07-0.30, $\left.P=1.1 \times 10^{-3}\right)$. MR analyses also revealed bidirectional associations between $\mathrm{CH}$ phenotypes and several blood cell counts and traits ${ }^{27}$, suggesting a shared underlying genetic liability to $\mathrm{CH}$ and pan-blood cell proliferation (Figs. $6 \mathrm{~b}$ and 7; Supplementary Tables 33 and 35). Finally, we found little evidence to support an association between genetic liability to $\mathrm{CH}$ and LTL (Supplementary Table 36), indicating that longer $\mathrm{LTL}$ was a cause rather than a consequence of $\mathrm{CH}$. 
medRxiv preprint doi: https://doi.org/10.1101/2022.01.06.22268846; this version posted January 6, 2022. The copyright holder for this preprint (which was not certified by peer review) is the author/funder, who has granted medRxiv a license to display the preprint in

It is made available under a CC-BY-NC-ND 4.0 International license.

\section{Discussion}

We present a large observational and genetic epidemiological analysis of $\mathrm{CH}$ and report a series of novel insights into the causes and consequences of this common aging-associated phenomenon. We increase the number of germline associations with $\mathrm{CH}$ in European-ancestry populations from four ${ }^{17}$ to 14 , reveal heterogeneity of associations by $\mathrm{CH}$ driver gene and clone size, and implicate putative new $\mathrm{CH}$ susceptibility genes, including CD164, ATM and SETBP1, through functional annotation. We also demonstrate that the $\mathrm{CH}$ GWAS signal is enriched at epigenetic marks specific to the hematopoietic system. The robustness of our GWAS analysis is further affirmed by our replication of previous European ancestry-specific $\mathrm{CH}$ associations ${ }^{17}$, the consistency of our estimates of $\mathrm{CH}$ heritability with previous reports ${ }^{17,77}$, and the fact that many of our lead variants are associated with related traits $27,32,60,78$.

New $\mathrm{CH}$ risk loci included the PARP1 coding variant rs1136410, where the $\mathrm{G}$ allele is protective for DNMT3A-CH and associated with reduced catalytic activity ${ }^{55}$ suggesting that this most common form of $\mathrm{CH}$ may be vulnerable to PARP inhibition, in keeping with the observed synergy between PARP and DNMT inhibitors ${ }^{79}$. At $14 q 32.13-T C L 1 A$, we replicate the reported association with DNMT3A-CH ${ }^{17}$ and identify a new genome-wide significant association with TET2-CH. Strikingly, however, we found that the association operates in the opposite direction for $T E T 2-C H$, versus DNMT3A-CH. This inverse relationship is tantalizing in light of recent observations that ageing has different effects on the dynamics of these two forms of $\mathrm{CH}$, resulting in TET2 $\mathrm{CH}$ becoming more prevalent than DNMT3A CH in those aged over 80 years ${ }^{80,81}$. Also notable in this light, is the finding of an association at the CD164 locus with DNMT3A, and a trend in the opposite direction for TET2-CH. As CD164 is expressed in the earliest $\mathrm{HSCS}^{53}$ and encodes an important regulator of $\mathrm{HSC}$ adhesion ${ }^{54,82}$, this proposes that HSC migration and homing may play important roles in $\mathrm{CH}$ pathogenesis. The reciprocal relationship of both TCL1A and CD164 with the two main CH subtypes, suggests that their expression needs to be tightly regulated to prevent the development of one or other subtype of $\mathrm{CH}$, making these loci important targets for hijack by the effects of somatic mutations.

The rich phenotypic data captured by the UKB, coupled with our genetic analysis of $\mathrm{CH}$ and external GWAS datasets, enabled us to explore associations of $\mathrm{CH}$ using multivariable regression and interrogate, at scale, potential causal relationships between $\mathrm{CH}$ and its putative risk factors and consequences using MR. This highlighted for the first time that smoking and longer telomere length are causal risk factors for $\mathrm{CH}$. These associations were valid across multiple $\mathrm{CH}$ subtypes and, in the case of smoking, corroborated by observational estimates. We also reveal that not only is genetic predisposition to $\mathrm{CH}$ causally associated with MPN risk, but it also increases the risk of lung, prostate, ovarian, oral/pharyngeal, and endometrial cancers. In these analyses, the use of two-sample MR protected against potential reverse causality arising from cancer therapy-induced selection pressure on hematopoietic clones ${ }^{83}$. These MR results suggest that genetic liability to $\mathrm{CH}$ may be a biomarker for development of cancer elsewhere in the body. An analogous relationship has previously been identified by MR for the association of genetic predisposition to $\mathrm{Y}$ chromosome loss in blood and solid tumor risk ${ }^{31}$.

We investigated the recently identified association of $\mathrm{CH}$ with blood-based epigenetic clocks ${ }^{84}$, using bi-directional MR and show that this association is likely to be causal in the direction from $\mathrm{CH}$ to epigenetic age acceleration. We also showed that genetic predisposition to $\mathrm{CH}$ was associated with elevated circulating levels of stem cell growth factor beta, a secreted sulfated glycoprotein that regulates primitive hematopoietic progenitor cells ${ }^{85}$. Finally, we unraveled a previously unreported association between genetic liability to $\mathrm{CH}$ and atrial fibrillation risk, which was also supported by our observational analysis. However, unlike previous reports based on significantly smaller sample numbers ${ }^{5,10,21}$, we did not find evidence in observational and MR analyses to support an association 
medRxiv preprint doi: https://doi.org/10.1101/2022.01.06.22268846; this version posted January 6 , 2022. The copyright holder for this preprint (which was not certified by peer review) is the author/funder, who has granted medRxiv a license to display the preprint in

It is made available under a CC-BY-NC-ND 4.0 International license.

409 between $\mathrm{CH}$ and $\mathrm{CAD}$ or ischemic stroke risk. However, our MR analyses indicated that higher BMI 410 and circulating apolipoprotein B levels were associated with TET2 and large clone $\mathrm{CH}$ risks, 411 respectively, with apolipoprotein $B$ being the key causal lipid risk factor for $C A D^{63,86}$. These associations 412 taken together with the fact that age and smoking are strong risk factors for $\mathrm{CH}$ raise the possibility 413 that previously reported associations of $\mathrm{CH}$ with $\mathrm{CAD}$ and stroke risks may suffer from residual 414 confounding.

415

416

417

418

419

420

421

422

423

424

425

426

427

428

429

430

Collectively, our findings substantially illuminate the landscape of inherited susceptibility to $\mathrm{CH}$ and provide new insights into the causes and consequences of $\mathrm{CH}$ with implications for human health and ageing.

\section{Methods}

\section{Study population and exome sequence data}

The United Kingdom Biobank (UKB) is a prospective longitudinal study containing in-depth genetic and health information from half a million UK participants. For this study, we have selected 200,453 individuals (200k) who had whole exome sequencing (WES) data available (age range: 38-72, median age: $58 ; 55 \%$ female; $83 \%$ White British). WES was generated in two batches, the first of approximately 50,000 samples $(50 k)^{87}$ and the second comprising an additional 150,000 samples $(150 k)^{19}$. Exomes were captured using the IDT xGen Exome Research Panel v1.0 including supplemental probes; a different IDT v1.0 oligo lot was used for each batch. Multiplexed samples were sequenced with dualindexed $75 \times 75$ bp paired-end reads on the Illumina NovaSeq 6000 platform using S2 (50k samples) and S4 (150k samples) flow cells. The 50k samples were firstly computed using FE protocol and reprocessed later to match the second batch of $150 \mathrm{k}$ sequences that were processed using a new improved unified OQFE pipeline. As the initial 50k samples were sequenced on S2 flow cells and with a different IDT v1.0 oligo lot than the remaining 150k samples, which were sequenced on S4 flow cells, we included the WES batch as a covariate in downstream analyses.

436

437

438

439

440

441

442

443

444

445

446

447

448

449

450

The UK Biobank study has been approved by the North West Multicentre Research Ethics Committee (11/NW/0382). All participants provided written informed consent. The current study has been conducted under approved UK Biobank application numbers 56844 and 29202.

\section{Whole exome sequence data processing, $\mathrm{CH}$ mutation calling and filtering}

CRAM files generated by the OQFE pipeline were obtained from UKB (Fields 23143-23144; www.ukbiobank.ac.uk). Variant-calling on WES data from 200,453 individuals was performed using Mutect2, Genome Analysis Toolkit (GATK) version 4.1.8.188. Briefly, Mutect2 was run in "tumor-only" mode with default parameters, over the exon intervals of 43 genes previously associated with $\mathrm{CH}$ (Supplementary Table 1). To filter out potential germline variants we used a population reference of germline variants generated from 1000 Genomes Project (1000GP) ${ }^{89}$ and the Genome Aggregation Database (gnomAD) ${ }^{90}$. All resources were obtained from the GATK Best practices repository (gs://gatkbest-practices/somatic-hg38). Raw variants called by Mutect 2 were filtered out with FilterMutectCalls using the estimated prior probability of a reading orientation artefact generated by LearnReadOrientationModel (GATK v.4.1.8.1). Putative variants flagged as 'PASS' using FilterMutectCalls or flagged as 'germline' if present at least 2 times with the 'PASS' flag in other samples were selected for filtering. Gene annotation was performed using Ensembl Variant Effect Predictor (VEP) (v.102) $)^{91}$. We required variants with a minimum number of alternate reads of 2 , evidence of the variant on both forward and reverse strand, a minimum depth of 7 reads for SNVs and 10 reads for short indels and substitutions and a minor allele frequency (MAF) lower than 0.001 (according to 1000GP phase 3 and gnomAD r2.1). For new variants, not previously described in the 
medRxiv preprint doi: https://doi.org/10.1101/2022.01.06.22268846; this version posted January 6, 2022. The copyright holder for this preprint (which was not certified by peer review) is the author/funder, who has granted medRxiv a license to display the preprint in perpetuity.

It is made available under a CC-BY-NC-ND 4.0 International license .

460 Catalogue of Somatic Mutations in Cancer (COSMIC; v.91) (2) $^{92}$ in the Database of Single Nucleotide 461 Polymorphisms (dbSNP; build 153) ${ }^{93}$, we used a minimum allele count per variant of 4, and a MAF 462 lower than $5 \times 10^{-5}$. From resulting variants, we selected those that: i) are included in a list of recurring 463 hotspots mutations associated with $\mathrm{CH}$ and myeloid cancer (Supplementary Table 2); ii) have been 464 reported as somatic mutations in hematological cancers at least 7 times in COSMIC; or iii) met the inclusion criteria of a predefined list of putative $\mathrm{CH}$ variants, previously described ${ }^{17,77}$ (Supplementary Table 3). We included previous variants flagged as germline by FilterMutectCalls if: 1) the number of cases in the cohort flagged as germline were lower than the ones flagged as PASS; and 2) at least one of the cases had a $P<0.001$ for a one-sided exact binomial test, where the null hypothesis was that the number of alternative reads supporting the mutation were $50 \%$ of the total number of reads $(95 \%$ for copy number equal to one), except for hotspot mutations that were all included. For the final list, we excluded all variants not present in COSMIC nor in the list of hotspots that had a MAF equal or higher than $5 \times 10^{-5}$ and either the mean variant allele fraction (VAF) of all cases was higher than 0.2 or the maximum VAF was lower than 0.1. Frameshift, nonsense, and splice-site mutations not present in COSMIC nor in the hotspot list were further excluded if for each variant none of the cases had a $P<0.001$ for a one-sided exact binomial test. A complete list of filtered variants is provided in Supplementary Table 4.

\section{Trait selection and modelling for the conventional observational multivariable regression analyses}

Phenotypes were downloaded in December 2020 and individual traits were pulled out from the whole phenotype file. Cancer, metabolic and cardiovascular disease (CVD) traits were generated combining individual traits and diagnosis dates based on disease definitions (Supplementary Table 8). For each definition of disease, the first diagnosis event that occurred in each trait was selected. Baseline was defined as the date of sample collection. The prevalent cases are those identified before the baseline, while incidence was defined as the events that occurred after the baseline. Unless specified, all regression models included age, sex, smoking status, WES batch and the first ten ancestry principal components as covariates. Blood cell counts and biochemical traits were $\log _{10}$ transformed and analyzed using a linear regression model, including the assessment center as covariate and, in the case of cholesterol and cholesterol species, the use of cholesterol lowering medication. Individuals with myeloid malignancies or hematological neoplasms at baseline were excluded from the analysis. For cancer, CVD and death risk, we performed a time-to-event regression analysis using the Cox proportional hazards model. The cancer/CVD/death event was used as an outcome and $\mathrm{CH}$ was considered as the exposure in these analyses. For CVD and death risk analyses, we also included body mass index, high-density lipoprotein cholesterol, low-density lipoprotein cholesterol, triglycerides, type 2 diabetes status, and hypertension status as covariates. Individuals with myeloid or other malignant neoplasms at baseline were excluded from all previous analyses. For associations between International Statistical Classification of Diseases and Related Health Problems 10th Revision (ICD-10) codes and $\mathrm{CH}$ status, a logistic regression model was used including age, sex, WES batch and the first ten ancestry principal components as covariates. Analyses were performed over the selected ICD-10 codes corresponding to diseases conditions (A to N), symptoms, signs, and abnormal clinical and laboratory findings $(R)$ and factors influencing health status ( $Z$ ). All analyses were performed using glm ( $R$ stats package v.4.0.2) and coxph ( $R$ survival package v.3.2-11) functions.

\section{Germline genotype data processing and genome-wide association analyses}

Germline genotype data used were from the UKB release that contained the full set of variants imputed into the Haplotype Reference Consortium ${ }^{94}$ and 1000GP ${ }^{89}$ reference panels and genotyped on the UK BiLEVE Axiom Array or UKB Axiom Array ${ }^{95}$. Derivation of the analytic sample for UK Biobank of individuals of European ancestries followed quality control (QC) steps described previously ${ }^{27}$ : after filtering genetic variants (call rate $\geq 99 \%$, imputation quality info score $>0.9$, Hardy-Weinberg 
medRxiv preprint doi: https://doi.org/10.1101/2022.01.06.22268846; this version posted January 6, 2022. The copyright holder for this preprint (which was not certified by peer review) is the author/funder, who has granted medRxiv a license to display the preprint in

It is made available under a CC-BY-NC-ND 4.0 International license.

511 equilibrium $P$-value $\geq 10^{-5}$ ) and participants (removal of genetic sex mismatches), we excluded 512 participants having non-European ancestries (self-report or inferred by genetics) or excess 513 heterozygosity (>3 standard deviations from the mean), and included only one of each set of related 514 participants (third-degree relatives or closer). After QC, we were left with 10,203 individuals with $\mathrm{CH}$ 515 and 173,918 individuals without $\mathrm{CH}$. The subset with $\mathrm{CH}$ included 5,185 and 2,041 individuals with 516 DNMT3A and TET2-mutant $\mathrm{CH}$, respectively, and 4,049 and 6,154 individuals with large (VAF $\geq 0.1)$ and small $(\mathrm{VAF}<0.1)$ clone size $\mathrm{CH}$, respectively. Association analyses were performed using noninfinitesimal linear mixed models implemented in BOLT-LMM ${ }^{96}$ with age at baseline, sex, and first 10 genetic principal components included as covariates.

Statistically independent lead variants for each $\mathrm{CH}$ phenotype were defined using linkage disequilibrium (LD)-based clumping with an $r^{2}$ threshold of 0.05 applied across all genotyped and imputed variants with $P<5 \times 10^{-8}$, imputation quality score $>0.6$, and $\mathrm{MAF}>1 \%$. This was implemented using the FUMA pipeline ${ }^{97}$. For the rare variant association scan, we used more stringent cut-offs of $P<10^{-9}$ and imputation quality score $>0.8$ to define lead variants but did not require LD-clumping since only one such association was identified. Approximate conditional analysis conditioning on the common $(\mathrm{MAF}>1 \%)$ lead variants was performed using the --cojo-cond flag in the Genome-wide Complex Trait Analysis (GCTA) v1.93 too ${ }^{25,98}$.

\section{Linkage disequilibrium score regression (LDSC)}

We used $\mathrm{LDSC}^{22}$ to estimate the narrow-sense heritability of $\mathrm{CH}$ on the liability scale assuming the population prevalence of $\mathrm{CH}$ to be $10 \%$ (based on the prevalence of $\mathrm{CH}$ in the UKB "200k" cohort as shown in Fig. 1b) and constraining the LDSC intercept to 1 . The intercept, which in its unconstrained form protects from bias due to population stratification, was constrained to 1 to provide more precise estimates given that there was little evidence of inflation in test statistics due to population structure in unconstrained analysis (unconstrained intercept estimated as 1.009 (s.e. $=0.0067$ ) and lambda genomic control factor of 0.999). We used the pre-computed 1000 Genomes phase 3 European ancestry reference panel LD score data set downloaded from alkesgroup.broadinstitute.org/LDSCORE for heritability estimation. We used the same LD scores and the --rg flag in LDSC to estimate the genetic correlation between the $\mathrm{CH}$ and mosaic chromosomal alteration GWAS summary statistics ${ }^{32}$. Cell-type group partitioned heritability analysis was performed as described in github.com/bulik/ldsc/wiki/Partitioned-Heritability using LD scores partitioned across 220 cell-typespecific annotations that were divided into 10 groups as previously described ${ }^{23}$ : central nervous system, cardiovascular, kidney, adrenal/pancreas, gastrointestinal, connective/bone, immune/hematopoietic, skeletal muscle, liver, and other. Each of the 10 groups contained cell-typespecific annotations for four histone marks: H3K9ac, H3K27ac, H3K4me1, and H3K4me3 ${ }^{23}$. We also used LD scores annotated as previously described ${ }^{99}$ based on open chromatin state (Assay for Transposase-Accessible Chromatin (ATAC)-seq) profiling by Corces et al. ${ }^{24}$ in various hematopoietic progenitor cells and lineages at different stages of differentiation.

\section{Gene-based and transcriptome-wide association studies, and network analyses}

We undertook genome-wide gene-level association analyses using two complementary approaches. First, we used multi-marker analysis of genomic annotation (MAGMA) that involves mapping germline variants to the genes they overlap, accounting for LD between variants, and performing a statistical multi-marker association test ${ }^{100}$. Second, we performed a transcriptome-wide association study (TWAS) using blood-based cis gene expression quantitative trait locus (eQTL) data on 31,684 individual $\mathrm{s}^{35}$ and summary-based Mendelian randomization (SMR) coupled with the heterogeneity in dependent instruments (HEIDI) colocalization test to identify germline genetic associations with $\mathrm{CH}$ 561 risk mediated via the transcriptome ${ }^{36}$. The gene-level genome-wide significance threshold in the 
medRxiv preprint doi: https://doi.org/10.1101/2022.01.06.22268846; this version posted January 6, 2022. The copyright holder for this preprint (which was not certified by peer review) is the author/funder, who has granted medRxiv a license to display the preprint in

It is made available under a CC-BY-NC-ND 4.0 International license .

562 MAGMA analyses was set at $P=2.6 \times 10^{-6}$ to account for testing 19,064 genes and for SMR was set at

$563 P=3.2 \times 10^{-6}$ after adjustment for testing 15,672 genes. Further, only genes with SMR $P<3.2 \times 10^{-6}$ and

564 HEIDI $P>0.05$ were declared genome-wide significant in the SMR analyses since the HEIDI $P>0.05$

565 strongly suggests colocalization of the GWAS and eQTL signals for a given gene ${ }^{36}$. The NetworkAnalyst

$5663.0^{39}$ webtool available at www.networkanalyst.ca was used for network analysis. All genes with $P<10^{-}$

$567{ }^{3}$ in each MAGMA analysis for overall, DNMT3A and TET2-mutant, and large and small clone $\mathrm{CH}$ were

568 used as input. The protein-protein interactome selected was STRING v10 ${ }^{101}$ with the recommended parameters (confidence score cut-off of 900 and requirement for experimental evidence to support the protein-protein interaction). The largest possible network was constructed from the seed genes/proteins and the interactome proteins as previously described ${ }^{39}$. Hub nodes were defined as nodes with degree centrality $\geq 10$ (i.e., nodes with at least 10 edges or connections to other proteins in the network as a measure of its importance in the network and consequently its biology). Pathway analysis of this largest network was conducted using the enrichment tool built into the NetworkAnalyst webtool and with the Reactome pathway repository ${ }^{102}$.

\section{Fine-mapping and target gene prioritization}

We fine-mapped the lead variant signals identified by the FUMA LD-clumping pipeline using the Probabilistic Identification of Causal Single Nucleotide Polymorphisms (PICS2) algorithm ${ }^{46,47}$ to identify candidate causal variants most likely to underpin each association. The PICS2 algorithm and webtool (pics2.ucsf.edu) computes the likelihood that each variant in LD with the lead variant is the true causal variant in the region by leveraging the fact that for variants associated merely due to LD, the strength of association scales asymptotically with correlation to the true causal variant ${ }^{46}$. We only retained variants with a PICS2 probability of $1 \%$ or more in our final list of fine-mapped candidate causal variants. We overlapped these fine-mapped variants with gene body annotations as previously described ${ }^{48}$ using GENCODE release $33^{103}$ (build 37 ) annotations after removing ribosomal protein genes (code and data adapted from github.com/sankaranlab/mpn-gwas). Fine-mapped variants were also overlapped with ATAC-seq peaks across 16 hematopoietic progenitor cell populations and ATACRNA count correlations calculated using Pearson coefficients for hematopoietic progenitor cell RNA counts of genes within $1 \mathrm{Mb}$ of the ATAC peaks were used to identify putative target genes of finemapped variants that overlapped ATAC-seq peaks. This pipeline has been used and described extensively before ${ }^{24,48-50}$, and we adapted the code and data for the pipeline from github.com/sankaranlab/mpn-gwas. We also looked up the SIFT ${ }^{51}$ and PolyPhen ${ }^{52}$ scores for these fine-mapped variants using the SNPnexus v4 web-based annotation tool (www.snp-nexus.org/v4) $)^{104}$ to identify coding variants with predicted functional consequences. Finally, we used the Open Targets Genetics resource ${ }^{45}$ (genetics.opentargets.org) to identify the most likely target gene of the lead variant at each locus as per Open Targets and used this in our omnibus target gene prioritization scheme described below.

In order to prioritize putative target genes at the $P_{\text {lead-variant }}<5 \times 10^{-8}$ loci identified by our GWAS of overall $\mathrm{CH}$, DNTM3A-CH, TET2-CH and large/small clone size $\mathrm{CH}$, we combined gene-level genomewide significant results from (1) MAGMA and (2) SMR with (3) protein-protein interaction network hub status of the gene, (4) variant-to-gene searches of the Open Targets database for lead variants, and overlap between fine-mapped variants and (5) gene bodies, (6) regions with accessible chromatin (ATAC-seq peaks) across 16 hematopoietic progenitor cell populations that were also correlated with nearby gene expression (RNA-seq) in the same cell populations, and (7) missense variant annotations from SIFT and PolyPhen. Genes nominated by at least two of the seven approaches were listed (except where only one of the seven methods nominated a single gene in a region in which case that gene was

610 listed) and the genes nominated by the largest number of approaches represented the most likely 611 targets at each locus. 
medRxiv preprint doi: https://doi.org/10.1101/2022.01.06.22268846; this version posted January 6 , 2022. The copyright holder for this preprint (which was not certified by peer review) is the author/funder, who has granted medRxiv a license to display the preprint in

It is made available under a CC-BY-NC-ND 4.0 International license.

613

614

615

616

617

618

619

620

621

622

623

624

625

626

627

628

629

630

631

632

633

634

635

636

637

638

639

640

641

642

643

644

645

646

647

648

649

650

651

652

653

654

655

656

657

658

659

660

661

662

663

\section{Phenome-wide association scan for lead variants}

We used PhenoScanner V2 ${ }^{33,34}$ available at www.phenoscanner.medschl.cam.ac.uk with catalogue set to "diseases \& traits", p-value set to " $5 \mathrm{E}-8$ ", proxies set to "EUR" and $r^{2}$ set to "0.8" to search for published phenome-wide associations between our lead variants or variants in strong linkage disequilibrium $\left(r^{2}>0.8\right)$ with the lead variants and other diseases and traits.

\section{Mendelian randomization analysis}

Mendelian randomization (MR ${ }^{105,106}$ uses germline variants as instrumental variables to proxy an exposure or potential risk factor and evaluate evidence for a causal effect of the exposure or potential risk factor on an outcome. Due to the random segregation and independent assortment of alleles at meiosis, MR estimates are less susceptible to bias from confounding factors as compared to conventional observational epidemiological studies. As the germline genome cannot be influenced by the environment after conception or by preclinical disease, MR estimates are also less susceptible to bias due to reverse causation. MR estimates represent the association between genetically predicted levels of exposures or risk factors and outcomes, as compared to conventional observational epidemiological estimates, which represent direct associations of the exposure or risk factor levels with outcomes. Effect allele harmonization across GWAS summary statistics datasets followed by twosample Mendelian randomization analyses were performed using the TwoSampleMR v0.5.6 $R$ package ${ }^{58}$. The $\mathrm{CH}$ phenotypes were considered as both exposures (to identify consequences of genetic liability to $\mathrm{CH}$ ) and outcomes (to identify risk factors for $\mathrm{CH}$ ). When considering $\mathrm{CH}$ phenotypes as outcomes, germline variants associated with putative risk factors or exposures at $P<5 \times 10^{-8}$ were used as genetic instruments for the risk factors/exposures, except for the appraisal of circulating cytokines and growth factors ${ }^{65}$ wherein variants associated with cytokines/growth factors at $P<10^{-5}$ were used as instruments. Inverse-variance weighted analysis ${ }^{107}$ was the primary analytic approach with pleiotropy-robust sensitivity analyses carried out using the MR-Egger ${ }^{108}$ and weighted median ${ }^{109}$ methods. A full list of external GWAS data sources used for MR analyses is provided in Supplementary Tables 30 and 31.

\section{Acknowledgements}

This work was funded by a joint grant from the Leukemia and Lymphoma Society (RTF6006-19) and the Rising Tide Foundation for Clinical Cancer Research (CCR-18-500), and by the Wellcome Trust (WT098051). SPK is supported by a United Kingdom Research and Innovation (UKRI) Future Leaders Fellowship (MR/T043202/1) and leads the somatic genomics theme of the Integrative Cancer Epidemiology Programme at the University of Bristol that is funded by Cancer Research UK (C18281/A29019). PMQ is funded by the Miguel Servet Program (CP20/00130). MAF is funded by a Wellcome Clinical Research Fellowship (WT098051). RL is supported by Cancer Research UK (C18281/A29019). PC is supported by a British Heart Foundation Clinical Training Research Fellowship. SB is supported by a Sir Henry Dale Fellowship jointly funded by the Wellcome Trust and the Royal Society (204623/Z/16/Z). GSV is supported by a Cancer Research UK Senior Cancer Fellowship (C22324/A23015) and work in his lab is also funded by the European Research Council, Kay Kendall Leukaemia Fund, Blood Cancer UK, and the Wellcome Trust. This research was conducted using the UK Biobank resource under applications 56844 and 29202. We thank the participants and investigators involved in the UK Biobank resource and in the other genome-wide association studies cited in this work who collectively made this research possible. 
medRxiv preprint doi: https://doi.org/10.1101/2022.01.06.22268846; this version posted January 6, 2022. The copyright holder for this preprint (which was not certified by peer review) is the author/funder, who has granted medRxiv a license to display the preprint in It is made available under a CC-BY-NC-ND 4.0 International license .

664

665

666

667

668

669

670

671

672

673

674

675

676

677

678

679

680

681

682

683

684

685

686

687

688

689

690

691

692

693

694

695

696

697

698

699

700

701

702

703

704

705

706

707

\section{Ethics Declarations}

Competing Interests

GSV is a consultant to STRM.BIO and AstraZeneca.

\section{Author Contributions}

SPK, PMQ, and GSV conceived, designed, and supervised the study. SPK and PMQ carried out data analyses and generated tables and figures. MG, MSV, and MAF helped with mutation calling and filtering. TJ and SB performed genome-wide association analyses. RL assisted with Mendelian randomization analyses. VI helped with UK Biobank data access and handling. SB and PC advised on Mendelian randomization analyses. CB and PC helped with UK Biobank trait selection and filtering. SPK, PMQ, and GSV drafted the manuscript with inputs from all authors. All authors approved the final version of the paper.

\section{Data Availability}

Individual-level UK Biobank data can be requested via application to the UK Biobank (https://www.ukbiobank.ac.uk). The $\mathrm{CH}$ call set will be returned to the UK Biobank to enable individual-level data linkage for approved UK Biobank applications.

\section{Code Availability}

Code used in this study is available at https://github.com/pmquiros/CH UKBiobank and https://github.com/siddhartha-kar/clonal-hematopoiesis.

\section{Figures, Extended Data Figures, and Figure Legends can be found from pages 21 to 31}

\section{References}

1. Zhang, L. \& Vijg, J. Somatic Mutagenesis in Mammals and Its Implications for Human Disease and Aging. Annu. Rev. Genet. 52, 397-419 (2018).

2. Martincorena, I. \& Campbell, P. J. Somatic mutation in cancer and normal cells. Science 349, 1483-1489 (2015).

3. Kakiuchi, N. \& Ogawa, S. Clonal expansion in non-cancer tissues. Nat. Rev. Cancer 21, 239-256 (2021).

4. Genovese, G. et al. Clonal hematopoiesis and blood-cancer risk inferred from blood DNA sequence. N. Engl. J. Med. 371, 2477-2487 (2014).

5. Jaiswal, S. et al. Age-related clonal hematopoiesis associated with adverse outcomes. N. Engl. J. Med. 371, 2488-2498 (2014).

6. McKerrell, T. et al. Leukemia-associated somatic mutations drive distinct patterns of age-related clonal hemopoiesis. Cell Rep. 10, 1239-1245 (2015).

7. Xie, M. et al. Age-related mutations associated with clonal hematopoietic expansion and malignancies. Nat. Med. 20, $1472-1478$ (2014).

8. Abelson, S. et al. Prediction of acute myeloid leukaemia risk in healthy individuals. Nature 559, 400-404 (2018). 
medRxiv preprint doi: https://doi.org/10.1101/2022.01.06.22268846; this version posted January 6, 2022. The copyright holder for this preprint (which was not certified by peer review) is the author/funder, who has granted medRxiv a license to display the preprint in It is made available under a CC-BY-NC-ND 4.0 International license .

9. Desai, P. et al. Somatic mutations precede acute myeloid leukemia years before diagnosis. Nat. Med. 24, 1015-1023 (2018).

710 10. Jaiswal, S. et al. Clonal Hematopoiesis and Risk of Atherosclerotic Cardiovascular Disease. N. Engl. J. Med. 377, 111-121 (2017).

11. Dorsheimer, L. et al. Association of Mutations Contributing to Clonal Hematopoiesis With Prognosis in Chronic Ischemic Heart Failure. JAMA Cardiol. 4, 25-33 (2019).

714 12. Jaiswal, S. \& Ebert, B. L. Clonal hematopoiesis in human aging and disease. Science 366, eaan4673 (2019).

13. Coombs, C. C. et al. Therapy-Related Clonal Hematopoiesis in Patients with Non-hematologic Cancers Is Common and Associated with Adverse Clinical Outcomes. Cell Stem Cell 21, 374-382.e4 (2017).

14. Gibson, C. J. et al. Clonal Hematopoiesis Associated With Adverse Outcomes After Autologous Stem-Cell Transplantation for Lymphoma. J. Clin. Oncol. 35, 1598-1605 (2017).

15. Meisel, M. et al. Microbial signals drive pre-leukaemic myeloproliferation in a Tet2-deficient host. Nature 557, 580-584 (2018).

16. Yoshizato, T. et al. Somatic Mutations and Clonal Hematopoiesis in Aplastic Anemia. N. Engl. J. Med. 373, 35-47 (2015).

17. Bick, A. G. et al. Inherited causes of clonal haematopoiesis in 97,691 whole genomes. Nature $586,763-768$ (2020).

18. Hinds, D. A. et al. Germ line variants predispose to both JAK2 V617F clonal hematopoiesis and myeloproliferative neoplasms. Blood 128, 1121-1128 (2016).

19. Szustakowski, J. D. et al. Advancing human genetics research and drug discovery through exome sequencing of the UK Biobank. Nat. Genet. 53, 942-948 (2021).

20. De-Morgan, A., Meggendorfer, M., Haferlach, C. \& Shlush, L. Male predominance in AML is associated with specific preleukemic mutations. Leukemia 35, 867-870 (2021).

21. Bick, A. G. et al. Genetic Interleukin 6 Signaling Deficiency Attenuates Cardiovascular Risk in Clonal Hematopoiesis. Circulation 141, 124-131 (2020).

731 22. Bulik-Sullivan, B. K. et al. LD Score regression distinguishes confounding from polygenicity in genome-wide association studies. Nat. Genet. 47, 291-295 (2015).

23. Finucane, H. K. et al. Partitioning heritability by functional annotation using genome-wide association summary statistics. Nat. Genet. 47, 1228-1235 (2015).

24. Corces, M. R. et al. Lineage-specific and single-cell chromatin accessibility charts human hematopoiesis and leukemia evolution. Nat. Genet. 48, 1193-1203 (2016).

737 25. Yang, J. et al. Conditional and joint multiple-SNP analysis of GWAS summary statistics identifies additional variants influencing complex traits. Nat. Genet. 44, 369-375, S1-3 (2012). 
medRxiv preprint doi: https://doi.org/10.1101/2022.01.06.22268846; this version posted January 6, 2022. The copyright holder for this preprint (which was not certified by peer review) is the author/funder, who has granted medRxiv a license to display the preprint in It is made available under a CC-BY-NC-ND 4.0 International license .

26. Walsh, T. G. et al. Loss of the exocyst complex component EXOC3 promotes hemostasis and accelerates arterial thrombosis. Blood Adv. 5, 674-686 (2021).

741 27. Astle, W. J. et al. The Allelic Landscape of Human Blood Cell Trait Variation and Links to Common Complex Disease. Cell 167, 1415-1429.e19 (2016).

28. Conti, D. V. et al. Trans-ancestry genome-wide association meta-analysis of prostate cancer identifies new susceptibility loci and informs genetic risk prediction. Nat. Genet. 53, 65-75 (2021).

29. Schmidt, M. K. et al. Age- and Tumor Subtype-Specific Breast Cancer Risk Estimates for CHEK2*1100delC Carriers. J. Clin. Oncol. 34, 2750-2760 (2016).

30. Ruth, K. S. et al. Genetic insights into biological mechanisms governing human ovarian ageing. Nature 596, 393-397 (2021).

31. Thompson, D. J. et al. Genetic predisposition to mosaic Y chromosome loss in blood. Nature 575, 652-657 (2019).

32. Zekavat, S. M. et al. Hematopoietic mosaic chromosomal alterations increase the risk for diverse types of infection. Nat. Med. 27, 1012-1024 (2021).

33. Kamat, M. A. et al. PhenoScanner V2: an expanded tool for searching human genotype-phenotype associations. (2016). doi:10.1101/447367.

36. Zhu, Z. et al. Integration of summary data from GWAS and eQTL studies predicts complex trait gene targets. Nat. Genet. 48, 481-487 (2016).

37. Ragu, C. et al. The transcription factor Srf regulates hematopoietic stem cell adhesion. Blood 116, 4464-4473 (2010).

38. Zink, F. et al. Clonal hematopoiesis, with and without candidate driver mutations, is common in the elderly. Blood 130, 742-752 (2017).

39. Zhou, G. et al. NetworkAnalyst 3.0: a visual analytics platform for comprehensive gene expression profiling and metaanalysis. Nucleic Acids Res. 47, W234-W241 (2019).

40. Cowen, L., Ideker, T., Raphael, B. J. \& Sharan, R. Network propagation: a universal amplifier of genetic associations. Nat. Rev. Genet. 18, 551-562 (2017).

41. Fernández-Tajes, J. et al. Developing a network view of type 2 diabetes risk pathways through integration of genetic, genomic and functional data. Genome Med. 11, 19 (2019). 
medRxiv preprint doi: https://doi.org/10.1101/2022.01.06.22268846; this version posted January 6, 2022. The copyright holder for this preprint (which was not certified by peer review) is the author/funder, who has granted medRxiv a license to display the preprint in It is made available under a CC-BY-NC-ND 4.0 International license . (2015).

44. Ostrander, E. L. et al. The GNASR201C mutation associated with clonal hematopoiesis supports transplantable hematopoietic stem cell activity. Exp. Hematol. 57, 14-20 (2018).

45. Ghoussaini, M. et al. Open Targets Genetics: systematic identification of trait-associated genes using large-scale genetics and functional genomics. Nucleic Acids Res. 49, D1311-D1320 (2021).

46. Taylor, K. E., Ansel, K. M., Marson, A., Criswell, L. A. \& Farh, K. K.-H. PICS2: Next-generation fine mapping via probabilistic identification of causal SNPs. Bioinformatics btab122 (2021).

47. Farh, K. K.-H. et al. Genetic and epigenetic fine mapping of causal autoimmune disease variants. Nature 518, 337-343 (2015).

48. Bao, E. L. et al. Inherited myeloproliferative neoplasm risk affects haematopoietic stem cells. Nature 586, 769-775 (2020).

49. Buenrostro, J. D. et al. Integrated Single-Cell Analysis Maps the Continuous Regulatory Landscape of Human Hematopoietic Differentiation. Cell 173, 1535-1548.e16 (2018).

50. Ulirsch, J. C. et al. Interrogation of human hematopoiesis at single-cell and single-variant resolution. Nat. Genet. 51, 683-693 (2019).

51. Vaser, R., Adusumalli, S., Leng, S. N., Sikic, M. \& Ng, P. C. SIFT missense predictions for genomes. Nat. Protoc. 11, 1-9 (2016).

52. Adzhubei, I. A. et al. A method and server for predicting damaging missense mutations. Nat. Methods 7, 248-249 (2010).

53. Pellin, D. et al. A comprehensive single cell transcriptional landscape of human hematopoietic progenitors. Nat. Commun. 10, 2395 (2019).

54. Zannettino, A. C. et al. The sialomucin CD164 (MGC-24v) is an adhesive glycoprotein expressed by human Blood 92, 2613-2628 (1998).

55. Wang, X.-G., Wang, Z.-Q., Tong, W.-M. \& Shen, Y. PARP1 Val762Ala polymorphism reduces enzymatic activity. Biochem.

798 56. Makishima, H. et al. Somatic SETBP1 mutations in myeloid malignancies. Nat. Genet. 45, 942-946 (2013).

799 57. Piazza, R. et al. Recurrent SETBP1 mutations in atypical chronic myeloid leukemia. Nat. Genet. 45, 18-24 (2013).

800 58. Hemani, G. et al. The MR-Base platform supports systematic causal inference across the human phenome. eLife 7, (2018). 
medRxiv preprint doi: https://doi.org/10.1101/2022.01.06.22268846; this version posted January 6, 2022. The copyright holder for this preprint (which was not certified by peer review) is the author/funder, who has granted medRxiv a license to display the preprint in It is made available under a CC-BY-NC-ND 4.0 International license .

802 59. Liu, M. et al. Association studies of up to 1.2 million individuals yield new insights into the genetic etiology of tobacco

803 and alcohol use. Nat. Genet. 51, 237-244 (2019).

804 60. Codd, V. et al. Polygenic basis and biomedical consequences of telomere length variation. (2021)

805 doi:10.1101/2021.03.23.21253516.

806

61. Pulit, S. L. et al. Meta-analysis of genome-wide association studies for body fat distribution in 694649 individuals of

807 European ancestry. Hum. Mol. Genet. 28, 166-174 (2019).

808 62. Mahajan, A. et al. Fine-mapping type 2 diabetes loci to single-variant resolution using high-density imputation and isletspecific epigenome maps. Nat. Genet. 50, 1505-1513 (2018).

810 63. Richardson, T. G. et al. Evaluating the relationship between circulating lipoprotein lipids and apolipoproteins with risk of coronary heart disease: A multivariable Mendelian randomisation analysis. PLoS Med. 17, e1003062 (2020).

812

64. McCartney, D. L. et al. Genome-wide association studies identify 137 genetic loci for DNA methylation biomarkers of aging. Genome Biol. 22, 194 (2021).

814 65. Ahola-Olli, A. V. et al. Genome-wide Association Study Identifies 27 Loci Influencing Concentrations of Circulating 815 Cytokines and Growth Factors. Am. J. Hum. Genet. 100, 40-50 (2017).

816 66. Staversky, R. J. et al. The Chemokine CCL3 Regulates Myeloid Differentiation and Hematopoietic Stem Cell Numbers. Sci. Rep. 8, 14691 (2018).

818 67. Horvath, S. \& Raj, K. DNA methylation-based biomarkers and the epigenetic clock theory of ageing. Nat. Rev. Genet. 19, 371-384 (2018).

820 68. Wang, Y. et al. Rare variants of large effect in BRCA2 and CHEK2 affect risk of lung cancer. Nat. Genet. 46, 736-741 (2014).

822 69. Schumacher, F. R. et al. Association analyses of more than 140,000 men identify 63 new prostate cancer susceptibility loci. Nat. Genet. 50, 928-936 (2018).

70. Phelan, C. M. et al. Identification of 12 new susceptibility loci for different histotypes of epithelial ovarian cancer. Nat. Genet. 49, 680-691 (2017).

826 71. Lesseur, C. et al. Genome-wide association analyses identify new susceptibility loci for oral cavity and pharyngeal cancer. Nat. Genet. 48, 1544-1550 (2016).

828 72. O'Mara, T. A. et al. Identification of nine new susceptibility loci for endometrial cancer. Nat. Commun. 9, 3166 (2018).

829 73. Nikpay, M. et al. A comprehensive 1,000 Genomes-based genome-wide association meta-analysis of coronary artery 830 disease. Nat. Genet. 47, 1121-1130 (2015).

831 74. Malik, R. et al. Multiancestry genome-wide association study of 520,000 subjects identifies 32 loci associated with stroke and stroke subtypes. Nat. Genet. 50, 524-537 (2018). 
medRxiv preprint doi: https://doi.org/10.1101/2022.01.06.22268846; this version posted January 6, 2022. The copyright holder for this preprint (which was not certified by peer review) is the author/funder, who has granted medRxiv a license to display the preprint in It is made available under a CC-BY-NC-ND 4.0 International license.

833 75. Shah, S. et al. Genome-wide association and Mendelian randomisation analysis provide insights into the pathogenesis of heart failure. Nat. Commun. 11, 163 (2020).

835 76. Nielsen, J. B. et al. Biobank-driven genomic discovery yields new insight into atrial fibrillation biology. Nat. Genet. 50, 1234-1239 (2018).

77. Fabre, M. A. et al. Concordance for clonal hematopoiesis is limited in elderly twins. Blood 135, 269-273 (2020).

838 78. Vuckovic, D. et al. The Polygenic and Monogenic Basis of Blood Traits and Diseases. Cell 182, 1214-1231.e11 (2020).

839 79. Muvarak, N. E. et al. Enhancing the Cytotoxic Effects of PARP Inhibitors with DNA Demethylating Agents - A Potential 840 Therapy for Cancer. Cancer Cell 30, 637-650 (2016).

841 80. Rossi, M. et al. Clinical relevance of clonal hematopoiesis in the oldest-old population. Blood blood.2021011320 (2021).

842 81. Fabre, M. A. et al. The longitudinal dynamics and natural history of clonal haematopoiesis. (2021) doi:10.1101/2021.08.12.455048.

844 82. Forde, S. et al. Endolyn (CD164) modulates the CXCL12-mediated migration of umbilical cord blood CD133+ cells. Blood 109, 1825-1833 (2007).

83. Bolton, K. L. et al. Cancer therapy shapes the fitness landscape of clonal hematopoiesis. Nat. Genet. 52, 1219-1226 (2020).

848 84. Nachun, D. et al. Clonal hematopoiesis associated with epigenetic aging and clinical outcomes. Aging Cell 20, e13366 (2021).

850 85. Hiraoka, A. et al. Stem cell growth factor: in situ hybridization analysis on the gene expression, molecular characterization and in vitro proliferative activity of a recombinant preparation on primitive hematopoietic progenitor cells. Hematol. J. 2, 307-315 (2001).

853 86. Zuber, V. et al. High-throughput multivariable Mendelian randomization analysis prioritizes apolipoprotein B as key lipid risk factor for coronary artery disease. Int. J. Epidemiol. 50, 893-901 (2021).

87. Van Hout, C. V. et al. Exome sequencing and characterization of 49,960 individuals in the UK Biobank. Nature 586, 749756 (2020).

857 88. Auwera, G. A. V. de \& O'Connor, B. D. Genomics in the cloud: using Docker, GATK, and WDL in Terra. (O'Reilly, 2020).

858 89. 1000 Genomes Project Consortium et al. A global reference for human genetic variation. Nature 526, 68-74 (2015).

859 90. Karczewski, K. J. et al. The mutational constraint spectrum quantified from variation in 141,456 humans. Nature $\mathbf{5 8 1}$, 434-443 (2020).

861 91. McLaren, W. et al. The Ensembl Variant Effect Predictor. Genome Biol. 17, 122 (2016).

862 92. Tate, J. G. et al. COSMIC: the Catalogue Of Somatic Mutations In Cancer. Nucleic Acids Res. 47, D941-D947 (2019).

863 93. Sherry, S. T. et al. dbSNP: the NCBI database of genetic variation. Nucleic Acids Res. 29, 308-311 (2001).

864 94. McCarthy, S. et al. A reference panel of 64,976 haplotypes for genotype imputation. Nat. Genet. 48, 1279-1283 (2016). 
medRxiv preprint doi: https://doi.org/10.1101/2022.01.06.22268846; this version posted January 6, 2022. The copyright holder for this preprint (which was not certified by peer review) is the author/funder, who has granted medRxiv a license to display the preprint in It is made available under a CC-BY-NC-ND 4.0 International license .

865 95. Bycroft, C. et al. The UK Biobank resource with deep phenotyping and genomic data. Nature 562, 203-209 (2018).

866 96. Loh, P.-R. et al. Efficient Bayesian mixed-model analysis increases association power in large cohorts. Nat. Genet. 47,

867 $284-290$ (2015).

868 97. Watanabe, K., Taskesen, E., van Bochoven, A. \& Posthuma, D. Functional mapping and annotation of genetic associations with FUMA. Nat. Commun. 8, 1826 (2017).

870 98. Yang, J., Lee, S. H., Goddard, M. E. \& Visscher, P. M. GCTA: a tool for genome-wide complex trait analysis. Am. J. Hum. Genet. 88, 76-82 (2011).

872

99. Finucane, H. K. et al. Heritability enrichment of specifically expressed genes identifies disease-relevant tissues and cell types. Nat. Genet. 50, 621-629 (2018).

874 100. de Leeuw, C. A., Mooij, J. M., Heskes, T. \& Posthuma, D. MAGMA: generalized gene-set analysis of GWAS data. PLoS Comput. Biol. 11, e1004219 (2015).

876 101. Szklarczyk, D. et al. STRING v10: protein-protein interaction networks, integrated over the tree of life. Nucleic $877 \quad$ Acids Res. 43, D447-452 (2015).

878 102. Jassal, B. et al. The reactome pathway knowledgebase. Nucleic Acids Res. 48, D498-D503 (2020).

879 103. Frankish, A. et al. GENCODE reference annotation for the human and mouse genomes. Nucleic Acids Res. 47,

880 D766-D773 (2019).

881 104. Oscanoa, J. et al. SNPnexus: a web server for functional annotation of human genome sequence variation (2020

882 update). Nucleic Acids Res. 48, W185-W192 (2020).

883 105. Davey Smith, G. \& Hemani, G. Mendelian randomization: genetic anchors for causal inference in epidemiological studies. Hum. Mol. Genet. 23, R89-98 (2014).

885 106. Davies, N. M., Holmes, M. V. \& Davey Smith, G. Reading Mendelian randomisation studies: a guide, glossary, and 886 checklist for clinicians. BMJ 362, k601 (2018).

887 107. Burgess, S., Butterworth, A. \& Thompson, S. G. Mendelian randomization analysis with multiple genetic variants 888 using summarized data. Genet. Epidemiol. 37, 658-665 (2013).

889 108. Bowden, J., Davey Smith, G. \& Burgess, S. Mendelian randomization with invalid instruments: effect estimation 890 and bias detection through Egger regression. Int. J. Epidemiol. 44, 512-525 (2015).

891 109. Bowden, J., Davey Smith, G., Haycock, P. C. \& Burgess, S. Consistent Estimation in Mendelian Randomization with 892 Some Invalid Instruments Using a Weighted Median Estimator. Genet. Epidemiol. 40, 304-314 (2016).

893 
medRxiv preprint doi: https://doi.org/10.1101/2022.01.06.22268846; this version posted January 6, 2022. The copyright holder for this preprint (which was not certified by peer review) is the author/funder, who has granted medRxiv a license to display the preprint in It is made available under a CC-BY-NC-ND 4.0 International license.

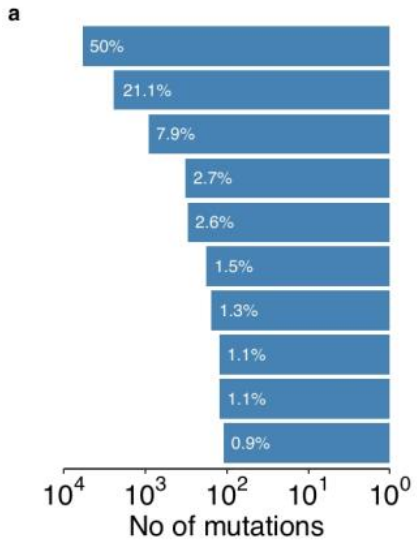

b

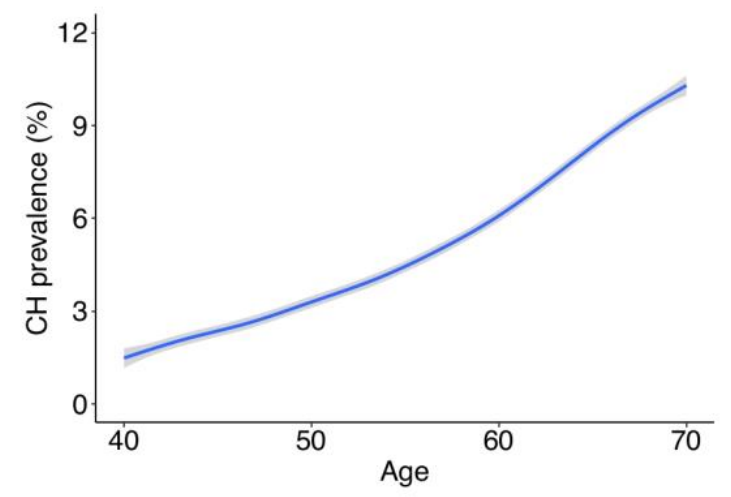

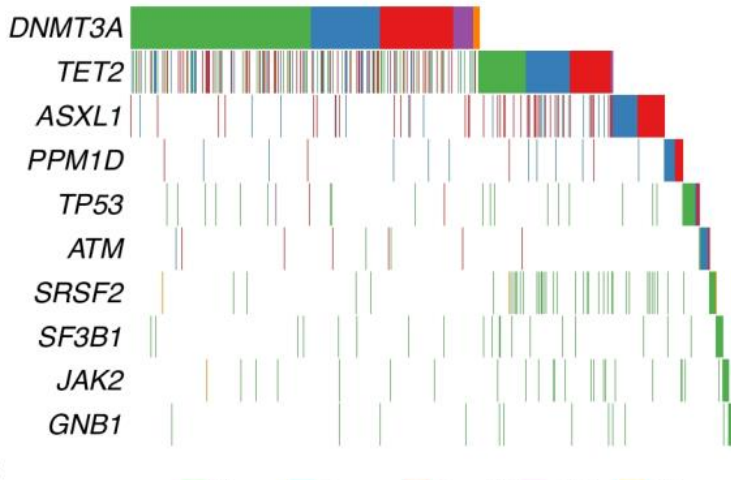

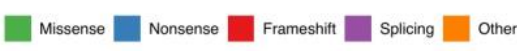

c

\section{Fig. 1: Characterization of $\mathrm{CH}$ in the UK Biobank.}

a, Composite plot summarizing mutations in the ten most common driver genes in 10,924 individuals with $\mathrm{CH}$. Each column in the waterfall plot represents a single individual, with mutation types color-coded. Bars on the left quantify mutations per gene as a percentage of all $\mathrm{CH}$ mutations identified. Violin plots on the right show the distribution of variant allele fractions (VAFs), with vertical lines represent the median and dots with horizontal lines the mean \pm standard deviation. $\mathbf{b}$, Prevalence of $\mathrm{CH}$ in the cohort with advancing age. The blue line represents the smoothed model fitted to a generalized additive model with 95\% confidence interval ( $\mathrm{Cl}$; grey shadow). c, Bar plot showing the female to males (F:M) ratio of $\mathrm{CH}$ carriers with mutations in the ten most common driver genes. "Other" represents the remaining driver genes grouped together and "Ctrl" the ratio for individuals without $\mathrm{CH}$. Dotted vertical line shows the $\mathrm{F}: \mathrm{M}$ ratio observed in the full cohort (F:M=1.2). $P$-values are from a Chi-square test comparing the distribution for each gene to "Ctrl". 
medRxiv preprint doi: https://doi.org/10.1101/2022.01.06.22268846; this version posted January 6, 2022. The copyright holder for this preprint (which was not certified by peer review) is the author/funder, who has granted medRxiv a license to display the preprint in perpetuity.

It is made available under a CC-BY-NC-ND 4.0 International license .

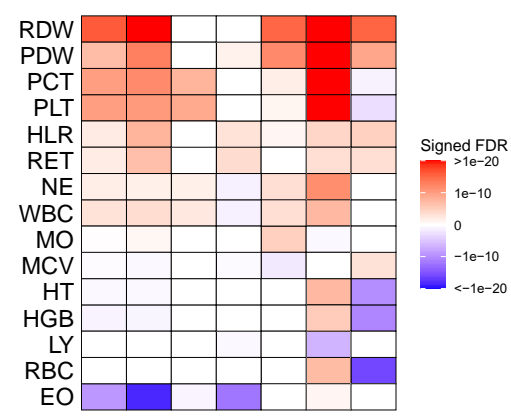

b

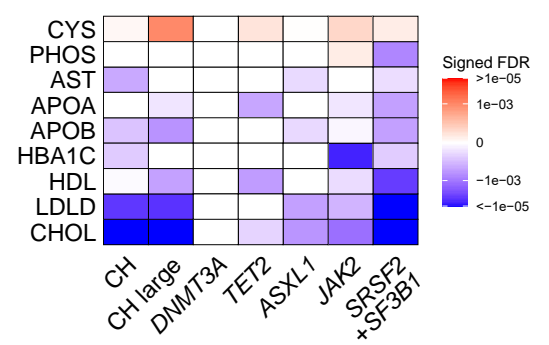

e
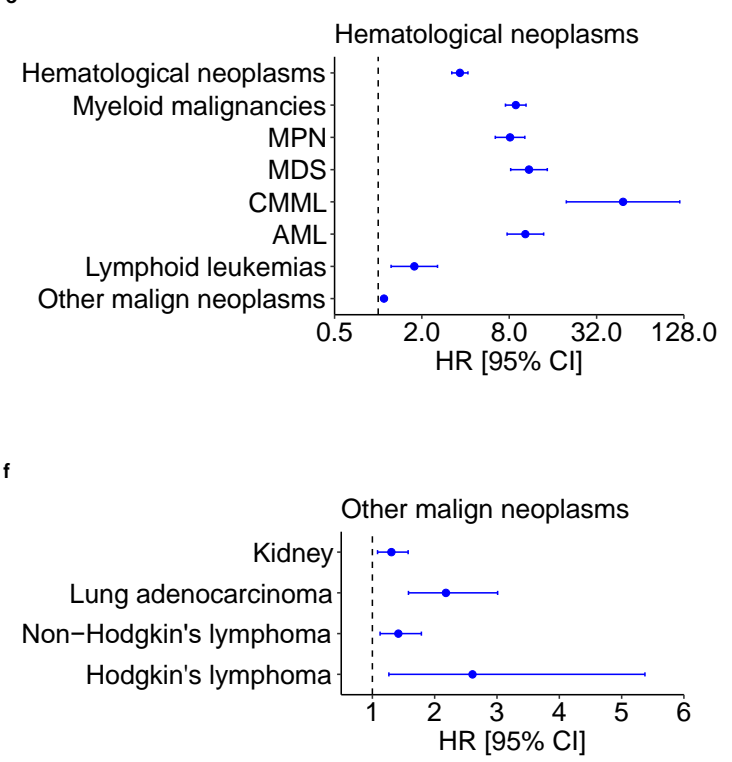
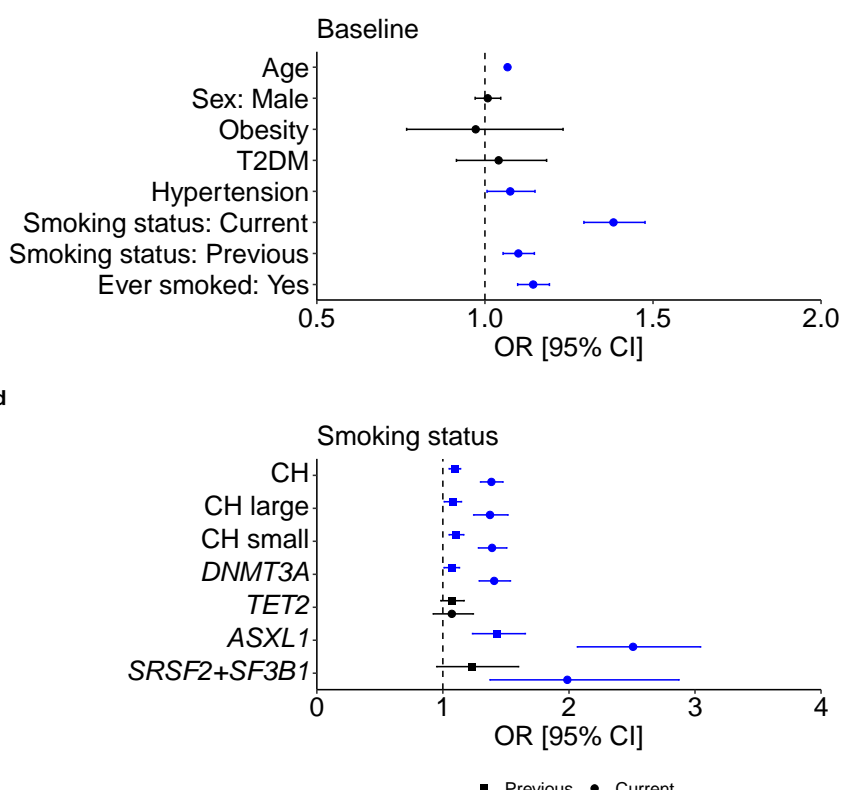

g
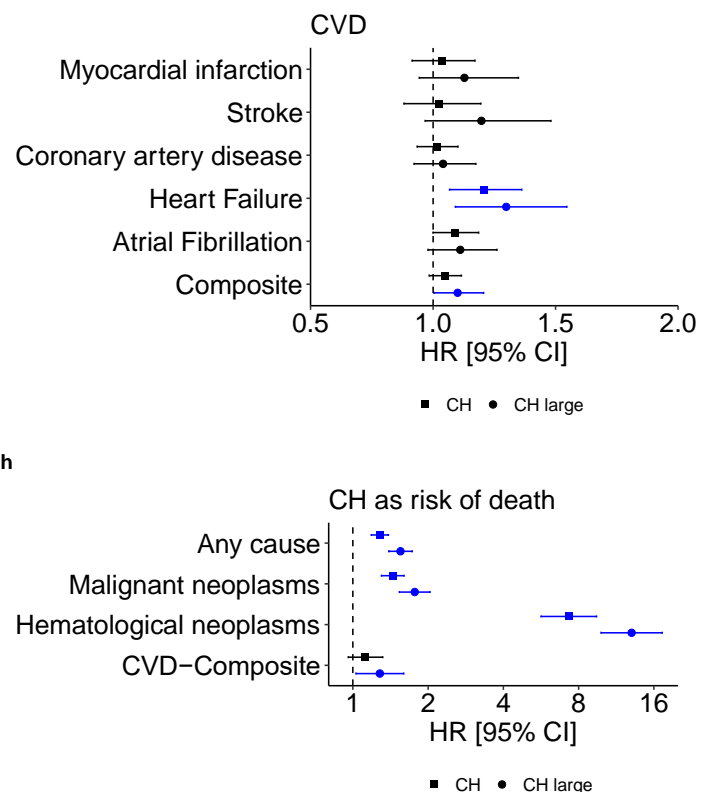

Fig. 2: Associations between $\mathrm{CH}$ and diverse traits/diseases. a-b, Heatmaps showing associations between overall $\mathrm{CH}, \mathrm{CH}$ with large clones, and $\mathrm{CH}$ driven by DNMT3A, TET2, ASXL1, $J A K 2$, and SRSF2+SF3B1 mutations and: $\mathbf{a}$, blood cell counts/indices or $\mathbf{b}$, biochemical analytes. Colors depict statistical significance of differences compared to individuals without $\mathrm{CH}$, as signed false discovery rate (FDR) values. c, Forest plot showing the odds ratios (ORs) for associations between $\mathrm{CH}$ and selected traits/diseases prevalent in UKB participants at baseline. $\mathbf{d}$, Forest plot showing the ORs for associations between $\mathrm{CH}$ subtypes and smoking status, for previous and current smokers. e-h, Forest plots showing the hazard ratios (HRs) for associations between $\mathrm{CH}$ at baseline and subsequent: e, hematological neoplasms, $\mathbf{f}$, other malignant neoplasms, $\mathbf{g}$, cardiovascular diseases, and $\mathbf{h}$, selected causes of death. For $\mathbf{g}$ and $\mathrm{h}$, both overall $\mathrm{CH}$ and $\mathrm{CH}$ characterized by large clones (" $\mathrm{CH}$ large") are shown. ORs/HR markers with a $P$-value $<0.05$ are depicted in blue. Error bars represent 95\% confidence intervals (Cls). Numerical values for ORs/HRs, $95 \% \mathrm{Cls}$, and $P$ values are reported in Supplementary Tables 5-13. Abbreviations: RDW, red blood cell (erythrocyte) distribution width;

918 PDW, platelet distribution width; PCT, plateletcrit; PLT, platelet count: WBC, white blood cell (leukocyte) count; NE, neutrophil count; HLR, high light scatter reticulocyte count; RET, reticulocyte count; MO, monocyte count; MCV, mean corpuscular volume; $\mathrm{HT}$, hematocrit percentage; HGB, hemoglobin concentration; LY, lymphocyte count; RBC, red blood cell (erythrocyte) count; EO, eosinophil count; CYS, cystatin C; PHOS, phosphate; AST, aspartate aminotransferase; HBA1C, glycosylated hemoglobin; APOA, apolipoprotein A; APOB, apolipoprotein B; HDL, HDL cholesterol; LDLD, LDL direct cholesterol; $\mathrm{CHOL}$, total cholesterol; T2DM, type 2 diabetes mellitus; MPN, myeloproliferative neoplasms; MDS, myelodysplastic syndromes; $\mathrm{AML}$, acute myeloid leukemia; $\mathrm{CMML}$, chronic myelomonocytic leukemia. 
medRxiv preprint doi: https://doi.org/10.1101/2022.01.06.22268846; this version posted January 6, 2022. The copyright holder for this preprint (which was not certified by peer review) is the author/funder, who has granted medRxiv a license to display the preprint in perpetuity.

It is made available under a CC-BY-NC-ND 4.0 International license .

a

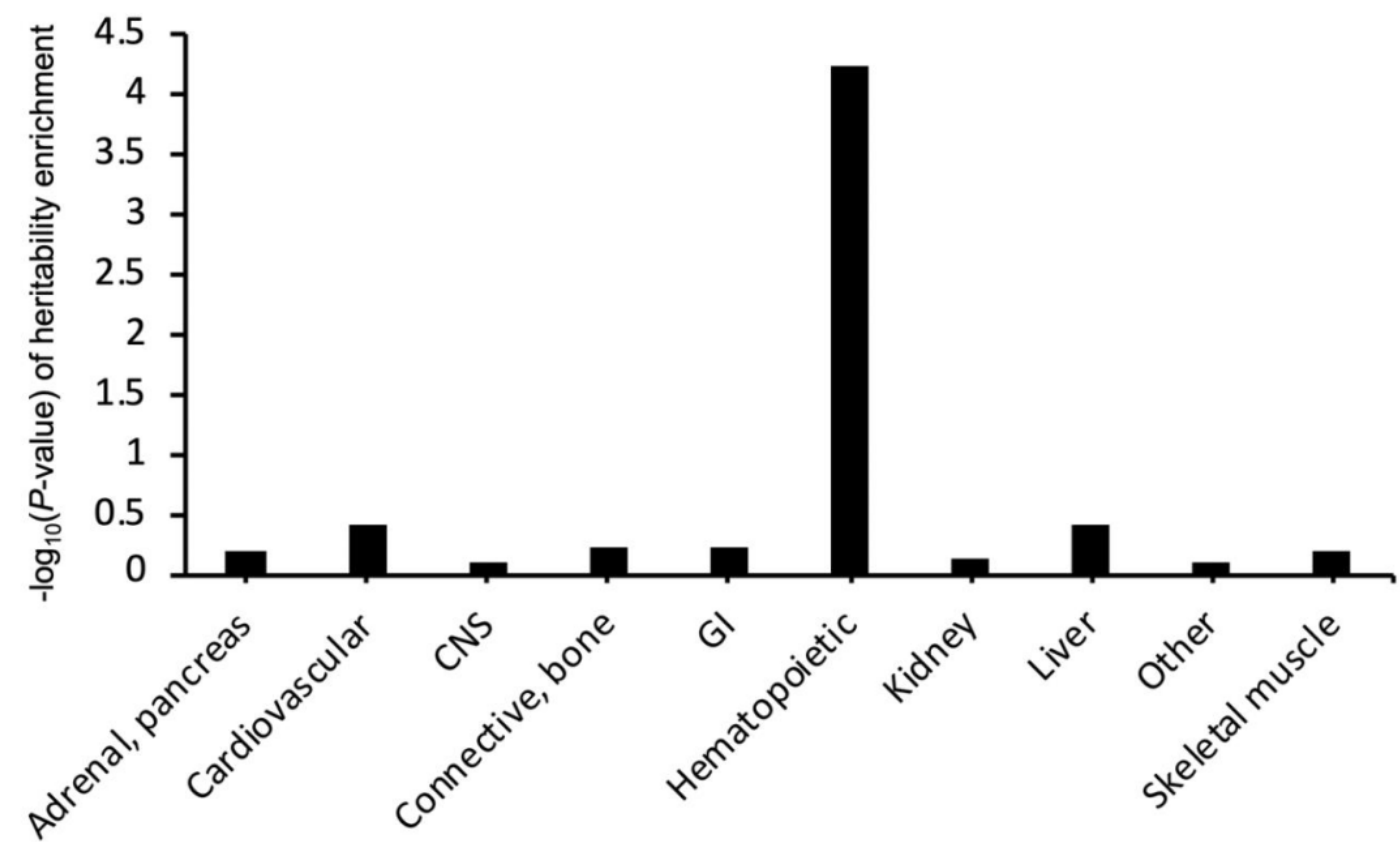

b

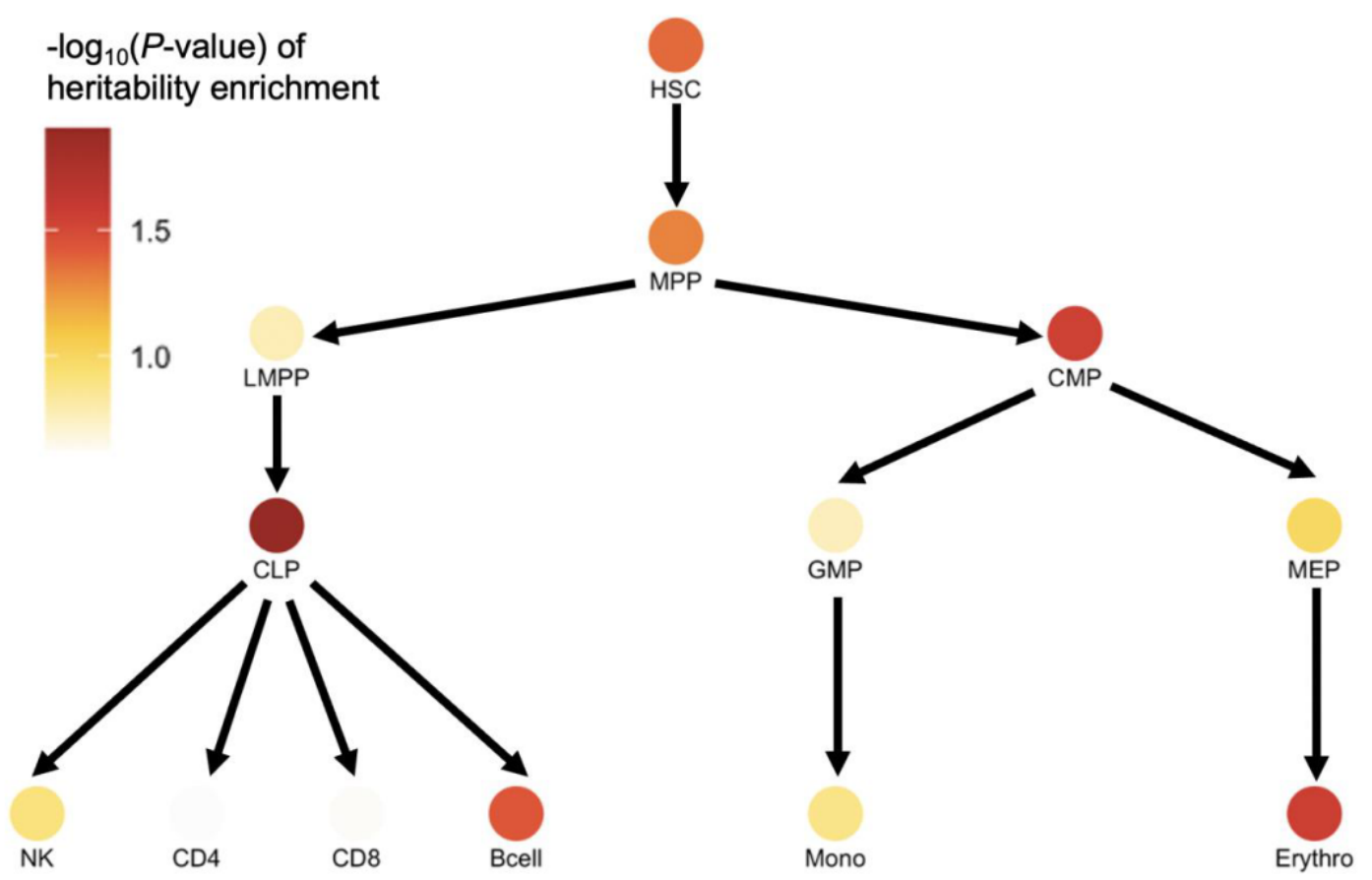

Fig. 3: Cell type-specific enrichment of the $\mathrm{CH}$ polygenic signal.

a, Heritability enrichment of $\mathrm{CH}$ across histone marks profiled in 10 cell type groups. b, Heritability enrichment of $\mathrm{CH}$ across open chromatin regions identified by ATAC-seq in hematopoietic progenitor cells/lineages at different stages of differentiation. Partitioned heritability cell-type group analysis in the LDSC software was used to compute these enrichments and corresponding $P$-values. The data underlying the figures is available in Supplementary Tables 14 and 15. Abbreviations: $\mathrm{CNS}$, central nervous system; GI, gastrointestinal; CLP, common lymphoid progenitor; CMP, common myeloid progenitor; MPP, multipotent progenitor; HSC, hematopoietic stem cell; GMP, granulocyte/macrophage progenitor; LMPP, lymphoidprimed multipotent progenitor; NK, natural killer cell; Mono, monocyte; Erythro, erythroid progenitor; LDSC, linkage disequilibrium score regression; ATAC-seq, (Assay for Transposase-Accessible Chromatin using sequencing). 
medRxiv preprint doi: https://doi.org/10.1101/2022.01.06.22268846; this version posted January 6, 2022. The copyright holder for this preprint (which was not certified by peer review) is the author/funder, who has granted medRxiv a license to display the preprint in It is made available under a CC-BY-NC-ND 4.0 International license .

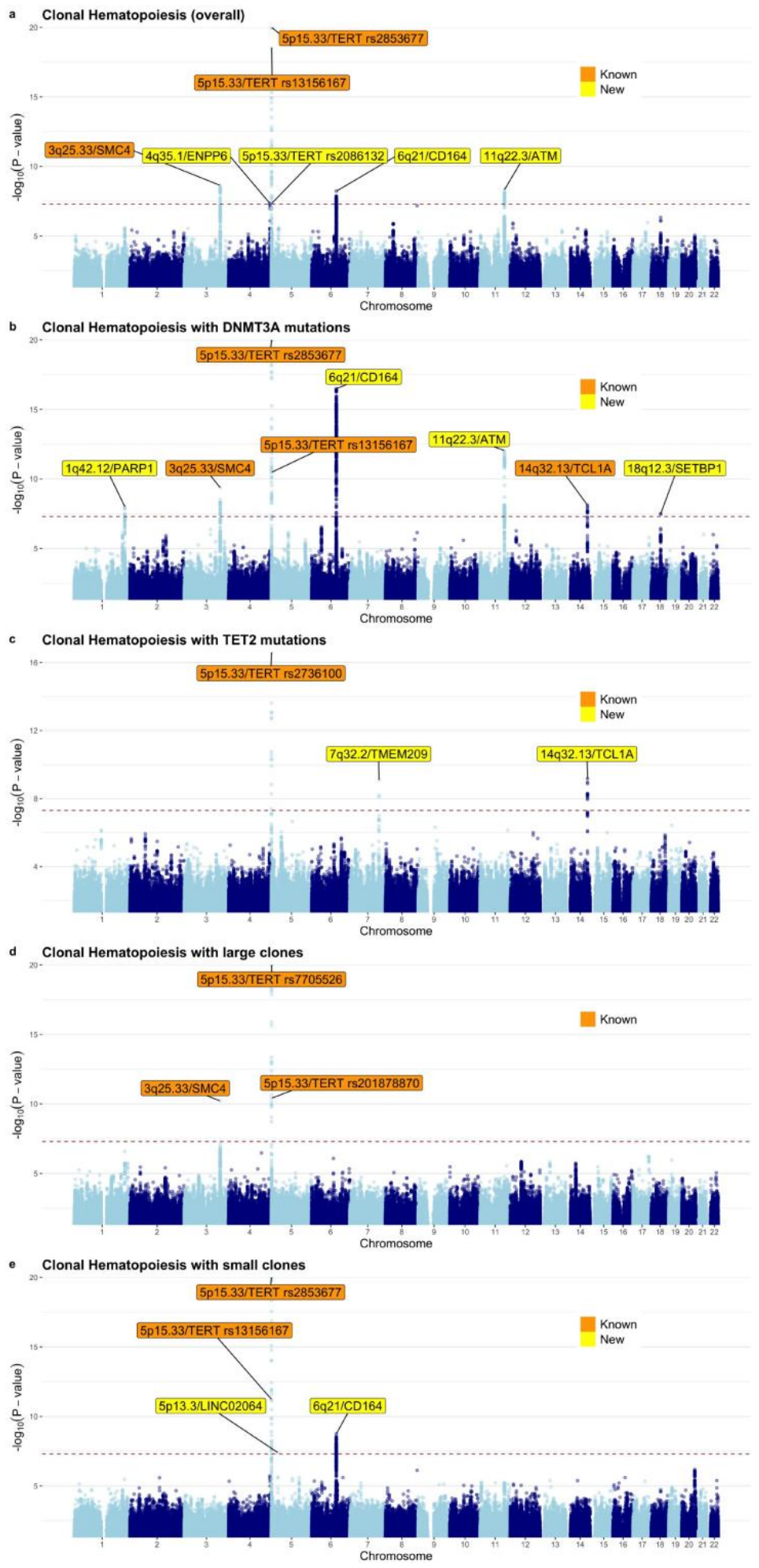

Fig. 4: Manhattan plots displaying genome-wide associations between common germline genetic variants and each of five CH traits.

The $Y$-axes depict $P$-values $\left(-\log _{10}\right)$ for associations derived from the non-infinitesimal mixed model association test implemented in BOLT-LMM. The X-axes depict chromosomal position on build 37 of the human genome (GRCh37). The dotted lines indicate the genome-wide significance threshold of $P=5 \times 10^{-8}$. Known (previously published) and new loci are indicated by cytoband and target gene (based on the prioritization exercise described in the text). Since there were multiple independent loci at 5p15.33 (LD $r^{2}<0.05$ ), we also label the 5 p15.33 signals using the lead variant rs number for each signal. Our prioritization exercise was focused on protein coding genes near each lead variant and since there were no protein coding genes within $1 \mathrm{Mb}$ of the lead variant at $5 \mathrm{p} 13.3$, we labeled this association using the nearest non-coding RNA. The $\mathrm{CH}$ traits corresponding to each Manhattan plot are: a, overall $\mathrm{CH}$. b, $\mathrm{CH}$ with mutant DNTM3A. c, $\mathrm{CH}$ with mutant TET2. d, $\mathrm{CH}$ with large clones. e, $\mathrm{CH}$ with small clones. 
medRxiv preprint doi: https://doi.org/10.1101/2022.01.06.22268846; this version posted January 6, 2022. The copyright holder for this preprint (which was not certified by peer review) is the author/funder, who has granted medRxiv a license to display the preprint in perpetuity.

It is made available under a CC-BY-NC-ND 4.0 International license.

a

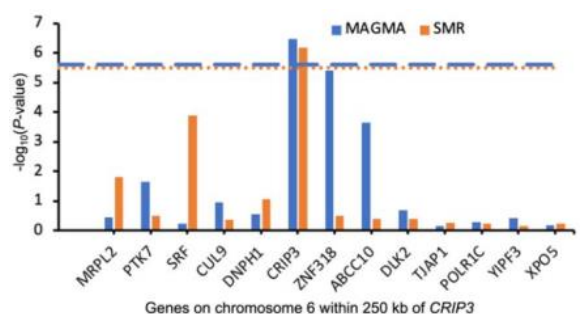

C



b

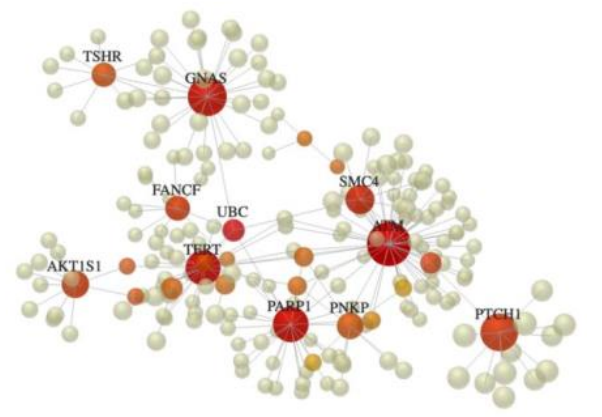

Fig. 5: Gene-level association and protein-protein interaction network analyses, and functional target gene prioritization matrix.

a, Gene-level associations in the $6 q 21$ region within 250 kilobases of $C R I P 3$, i.e., between GRCh37 positions 43,017,448 and $43,526,535$ on chromosome 6 . The X-axis lists all the genes in this region that were tested by both MAGMA and SMR. CRIP3 was the only gene located more than one megabase away from a GWAS-identified lead variant that was found to be associated with $\mathrm{CH}$ at gene-level genome-wide significance by both MAGMA and SMR. The Y-axis depicts the $P$-value (- $\left.\log _{10}\right)$ for association in the MAGMA and SMR analyses. The gene-level genome-wide significance threshold in MAGMA $\left(P=2.6 \times 10^{-}\right.$ ${ }^{6}$ after accounting for 19,064 genes tested) is indicated by the blue dashed line and in SMR $\left(P=3.2 \times 10^{-6}\right.$ after accounting for 15,672 genes tested) by the orange dotted line. Both CRIP3 and SRF had SMR HEIDI $P>0.05$ indicating colocalization of the GWAS and expression quantitative trait locus associations. b, Largest sub-network of genes/proteins associated with overall $\mathrm{CH}$ risk. All genes $(\mathrm{n}=57)$ with $P_{\text {MAGMA }}<0.001$ in the overall $\mathrm{CH}$ MAGMA analysis were mapped to proteins and used as "seeds" for network construction that was done by integrating high-confidence protein-protein interactions from the STRING database. The largest sub-network constructed contained 13 of the 57 seed proteins and included 210 nodes and 231 edges. The colored nodes indicate seed proteins that interact with at least two other proteins in this sub-network with the intensity of redness increasing with number of interacting proteins. Seed proteins that interact with six or more other proteins in the sub-network are named above their corresponding node. c, Matrix of target genes (protein coding) prioritized by seven approaches (Open Targets, fine-mapped variant-gene body overlap, MAGMA, SMR, network analysis hub, fine-mapped variant-ATAC-seq peak overlap followed by ATAC-RNA-seq correlation, and SIFT/PolyPhen scores) across the loci identified in this study. Only genes prioritized by at least two methods are shown, with the exception of SETBP1 that is shown despite being prioritized by only one method since it was the only gene prioritized at 18q12.3 and also happens to be an occasional somatic driver of $\mathrm{CH}$. There were no protein coding genes within $1 \mathrm{Mb}$ of the new small clone $\mathrm{CH}$ lead variant rs 72755524 at 5 p13.3 (nearest non-protein coding gene: LINCO2O64, nearest protein coding gene: $C D H 6$ ) and this locus is not shown in the matrix. Abbreviations: MAGMA, multi-marker analysis of genomic annotation; SMR, summary-based Mendelian randomization; HEIDI, heterogeneity in dependent instruments test; SIFT, Sorting Tolerant From Intolerant. 
medRxiv preprint doi: https://doi.org/10.1101/2022.01.06.22268846; this version posted January 6, 2022. The copyright holder for this preprint (which was not certified by peer review) is the author/funder, who has granted medRxiv a license to display the preprint in It is made available under a CC-BY-NC-ND 4.0 International license.

a

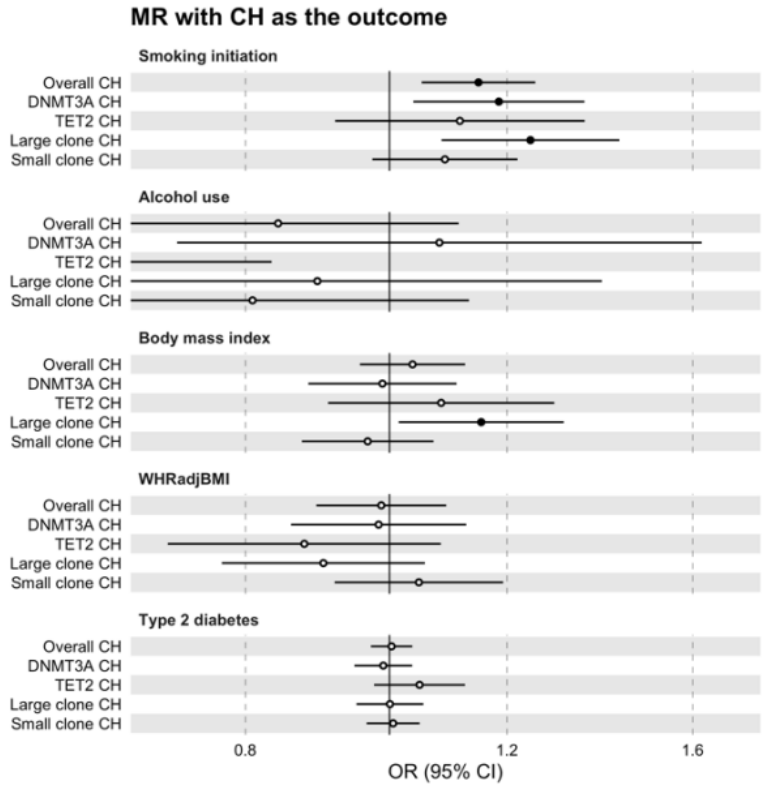

b

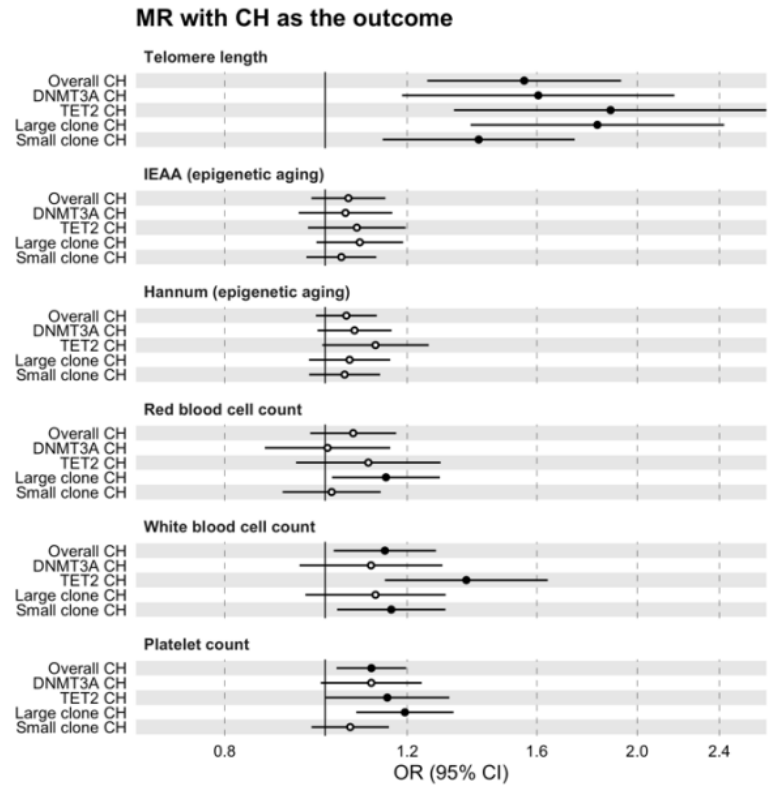

C

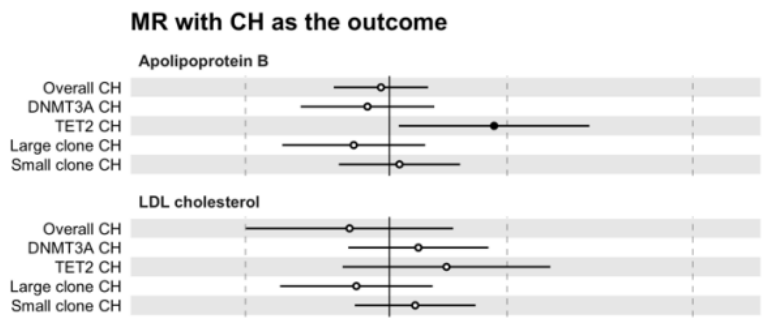

Apolipoprotein A-I

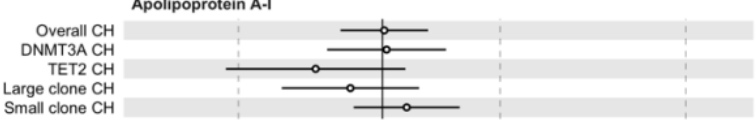

HDL cholesterol

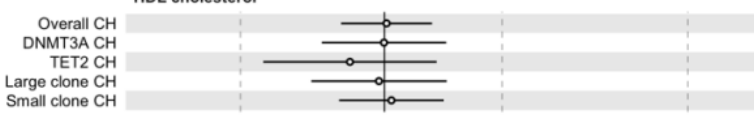

Triglycerides

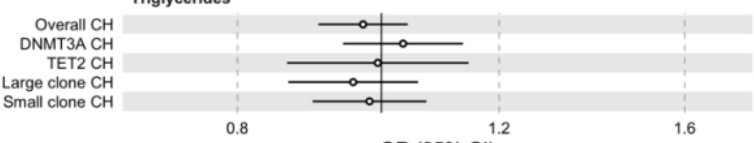

Fig. 6: Two-sample inverse-variance-weighted Mendelian randomization forest plots with $\mathrm{CH}$ traits as outcomes.

(i) standard deviation unit for continuous exposures (alcohol use in

drinks per week, body mass index, waist-to-hip ratio adjusted for body mass index (WHRadjBMI) (a); leukocyte telomere length, two epigenetic aging traits, red cell, white cell and platelet counts (b), and five circulating lipid traits (c)) and (ii) logodds unit for binary exposures (smoking initiation (ever having smoked regularly) and genetic liability to type 2 diabetes (a)). Details of units are provided in Supplementary Table 30. OR markers with corresponding $P$-value $<0.05$ are represented by filled circles. Error bars represent $95 \%$ confidence intervals (Cls). Full results, including sensitivity analyses, are presented in Supplementary Tables 32, 33, and 34. Abbreviations: MR, Mendelian randomization; $\mathrm{CH}$, clonal hematopoiesis; WHRadjBMI, waist-to-hip ratio adjusted for body mass index; LDL, low-density lipoprotein cholesterol; HDL, high-density lipoprotein cholesterol; IEAA, intrinsic epigenetic age acceleration. 
medRxiv preprint doi: https://doi.org/10.1101/2022.01.06.22268846; this version posted January 6, 2022. The copyright holder for this preprint (which was not certified by peer review) is the author/funder, who has granted medRxiv a license to display the preprint in It is made available under a CC-BY-NC-ND 4.0 International license .

a
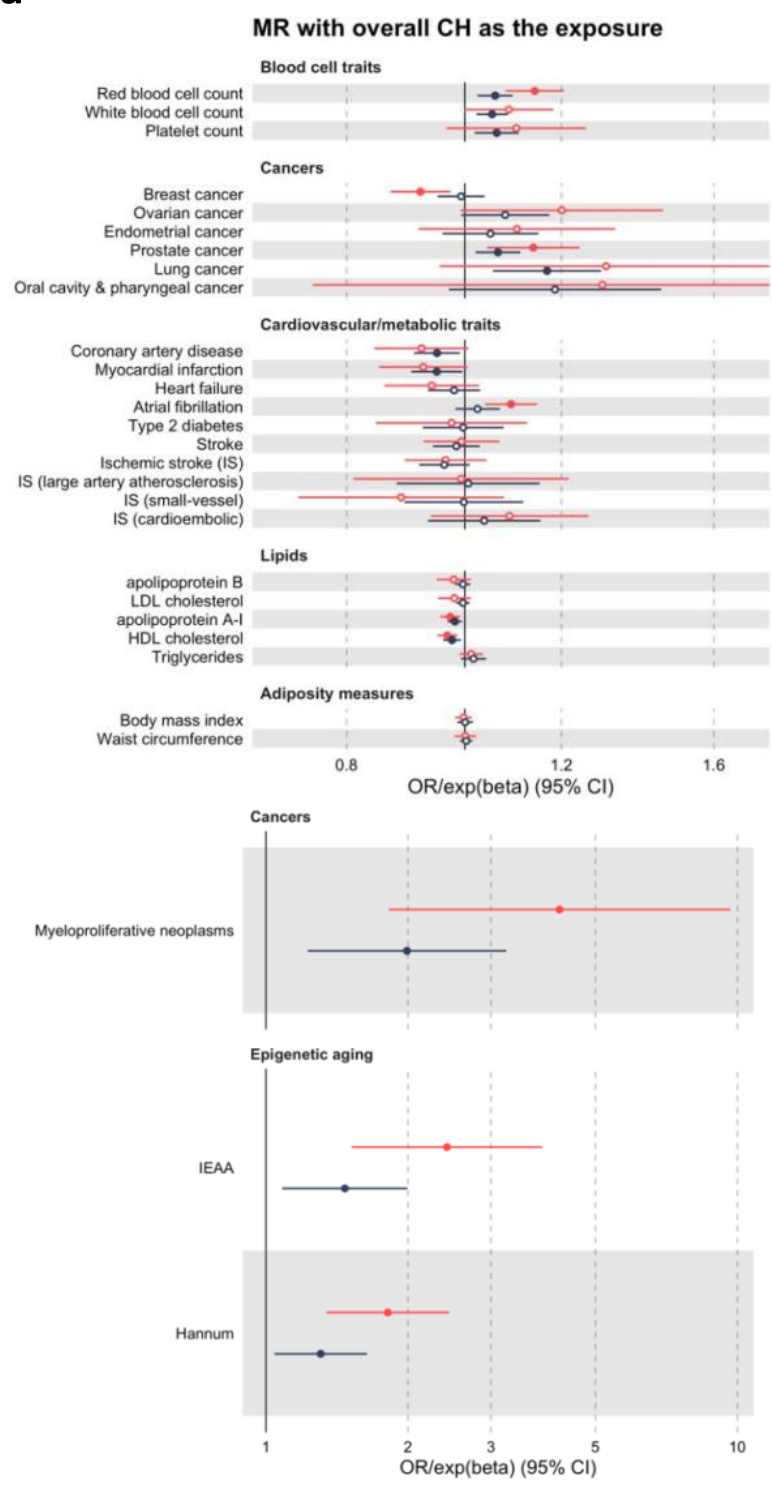

Instrument $-\mathrm{P}<5 \mathrm{e}-8$ - $\mathrm{P}<1 \mathrm{e}-5$ b
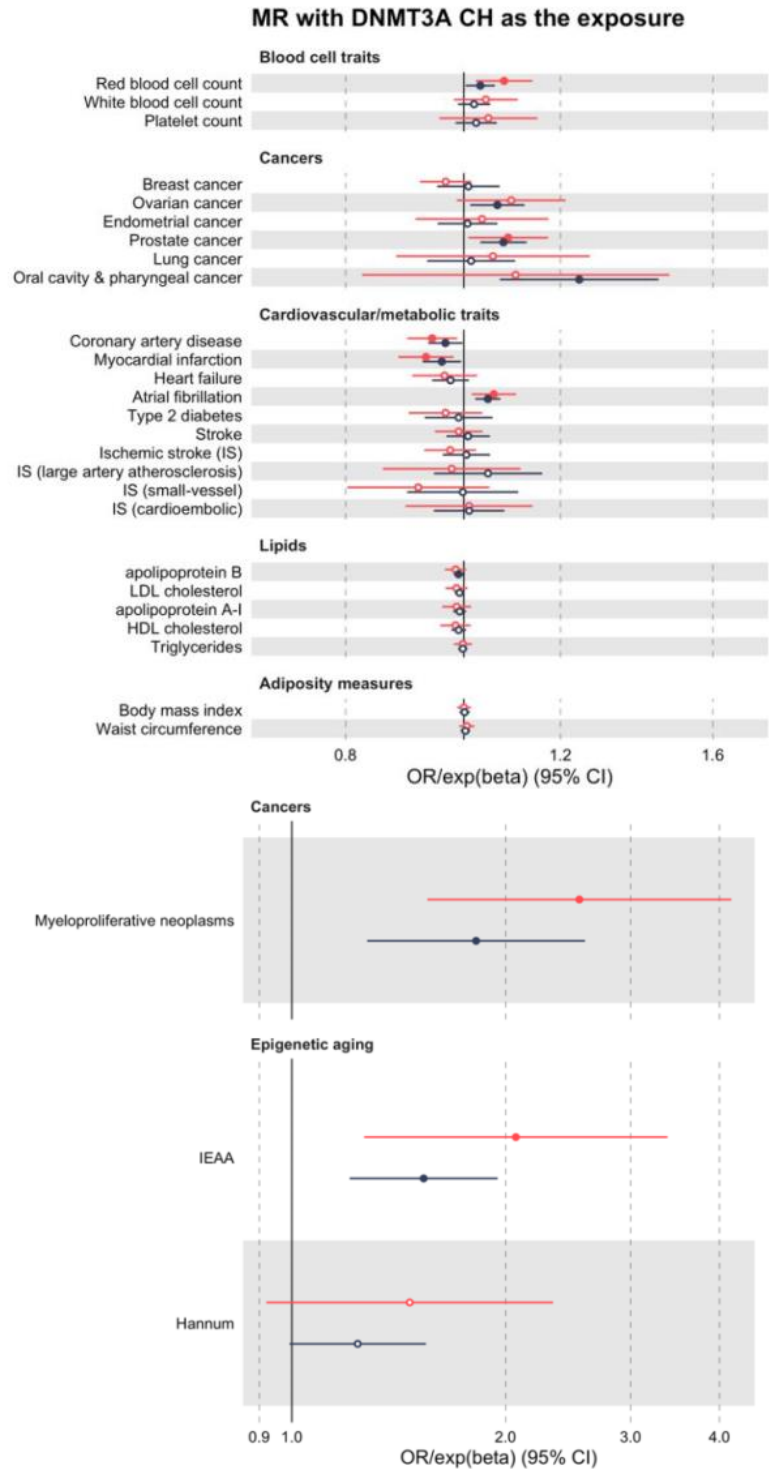

Instrument $-\mathrm{P}<5 \mathrm{e}-8 \quad \mathrm{P}<1 \mathrm{e}-5$

Fig. 7: Two-sample inverse-variance-weighted Mendelian randomization forest plots with $\mathrm{CH}$ traits as exposures.

Forest plots with odds ratio (OR) markers (for cancers and cardiovascular/metabolic traits) or exponentiated beta coefficient (exp(beta)) markers (for blood cell traits, lipids, adiposity measures, and epigenetic aging indices). ORs/exp(betas) are represented as per log-odds unit increase in genetic liability to a, overall CH, or b, DNMT3A CH. OR/exp(beta) markers with corresponding $P$-value $<0.05$ are represented by filled circles. Error bars represent $95 \%$ confidence intervals (Cls). Red markers and error bars represent results using genetic instruments comprised exclusively of genome-wide significant $\left(P<5 \times 10^{-8}\right)$ variants. Black markers and error bars represent results when using genome-wide significant and sub-genomewide significant $\left(P<10^{-5}\right)$ variants in the genetic instrument. Large effect size estimates (ORs/exp(betas)) are shown in the lower panels. Full results, including sensitivity analyses, are presented in Supplementary Tables 35 and 36 . Abbreviations: MR, Mendelian randomization; IS, ischemic stroke; LDL, low-density lipoprotein cholesterol; HDL, high-density lipoprotein cholesterol; IEAA, intrinsic epigenetic age acceleration. 
medRxiv preprint doi: https://doi.org/10.1101/2022.01.06.22268846; this version posted January 6, 2022. The copyright holder for this preprint (which was not certified by peer review) is the author/funder, who has granted medRxiv a license to display the preprint in perpetuity.

It is made available under a CC-BY-NC-ND 4.0 International license

a

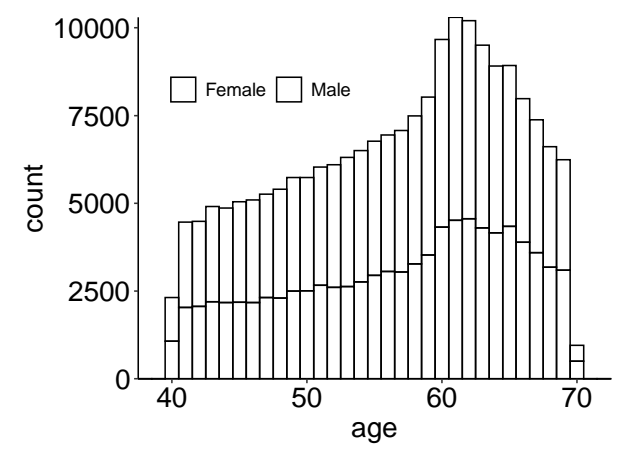

d

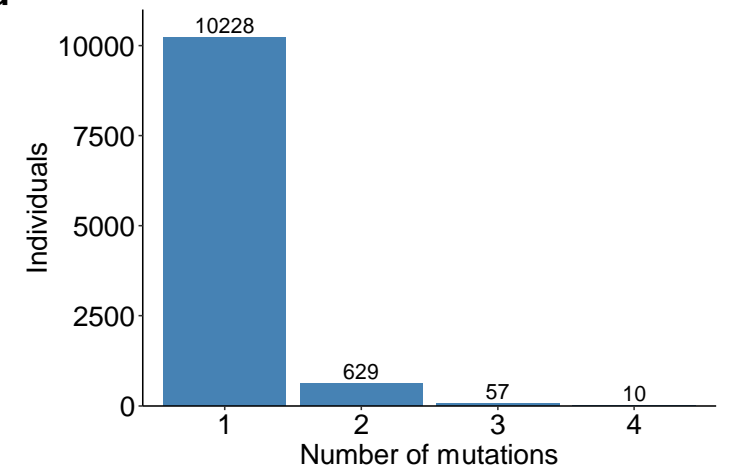

$\mathbf{f}$

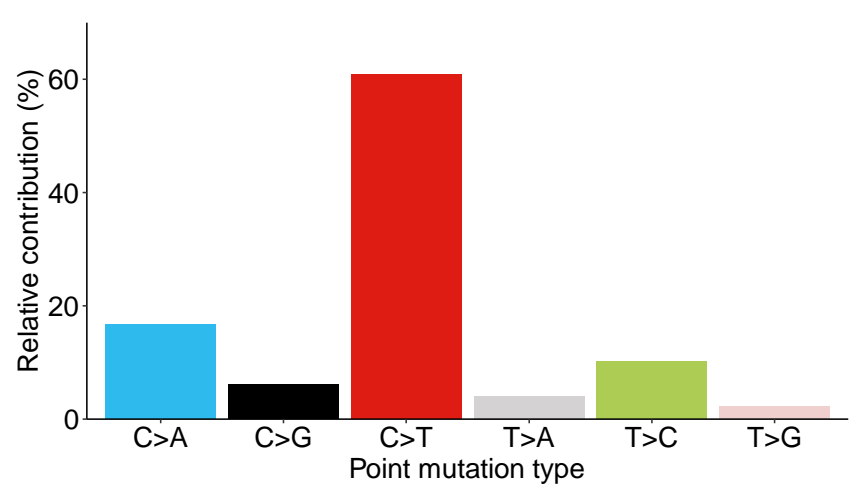

h

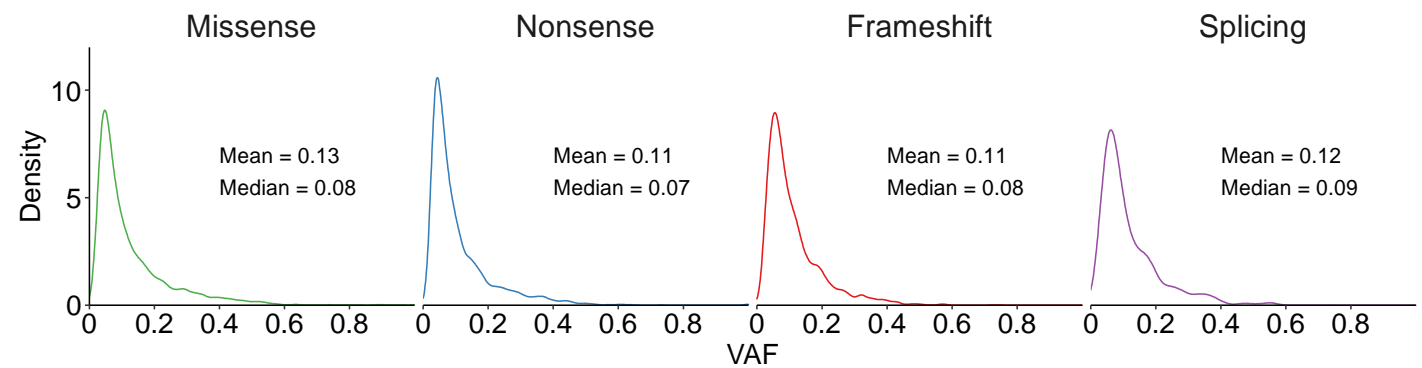

b

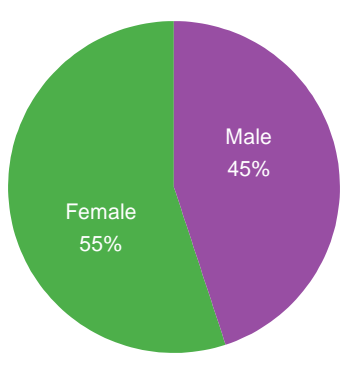

e c
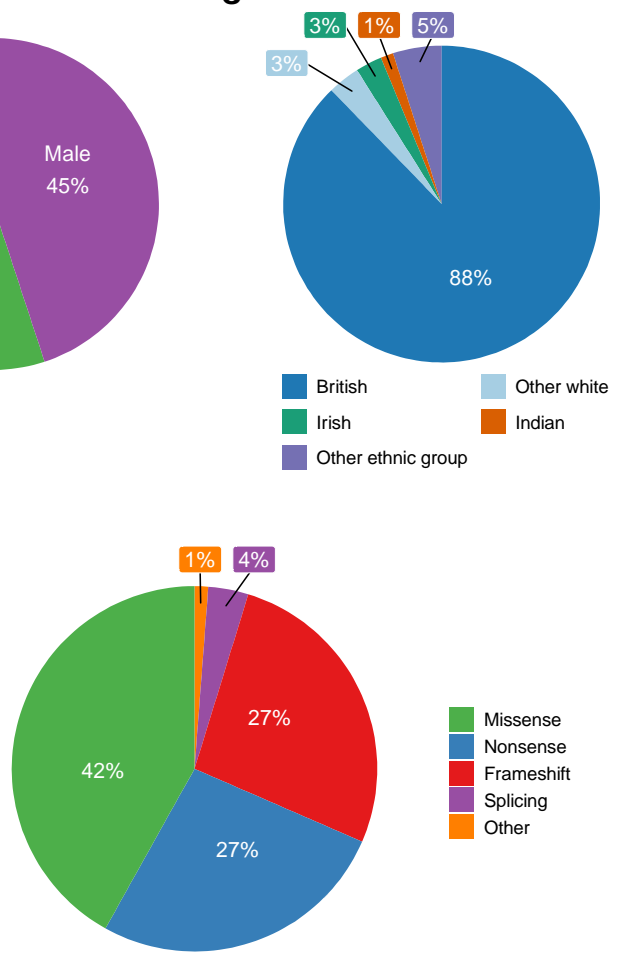

g

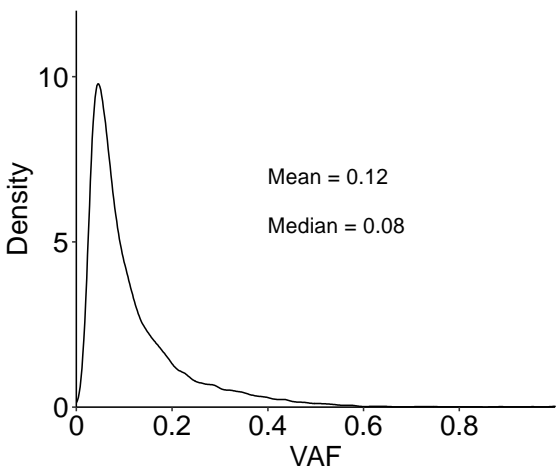

\section{Extended Data Fig. 1: Characterization of $\mathrm{CH}$ in the UK Biobank.}

a, Histogram stratified by sex showing the age-distribution of individuals in the UKB cohort $(n=200,453)$. b, Overall percentage of females and males in the UKB cohort. c, Percentage of the most common self-reported ethnic groups in the UKB cohort. Ethnic groups with a frequency lower than $1 \%$ were grouped under the "Other ethnic group" category. $\mathbf{d}$, Number of individuals with 1, 2, 3, and 4 somatic mutations. More than $90 \%$ of individuals with $\mathrm{CH}$ had only one driver mutation identified. e, Percentages of different $\mathrm{CH}$ mutation types identified. $\mathbf{f}$, Relative prevalence of each of the six base substitution types amongst the identified $\mathrm{CH}$ mutations. g, Density plot showing the variant allele fraction (VAF) distribution of all $\mathrm{CH}$ somatic mutations. $\mathbf{h}$, Density plot showing similar VAF distribution for different mutation types. Mean and median are indicated for $\mathrm{g}$ and $\mathrm{h}$. 
medRxiv preprint doi: https://doi.org/10.1101/2022.01.06.22268846; this version posted January 6, 2022. The copyright holder for this preprint (which was not certified by peer review) is the author/funder, who has granted medRxiv a license to display the preprint in perpetuity.

It is made available under a CC-BY-NC-ND 4.0 International license .

a

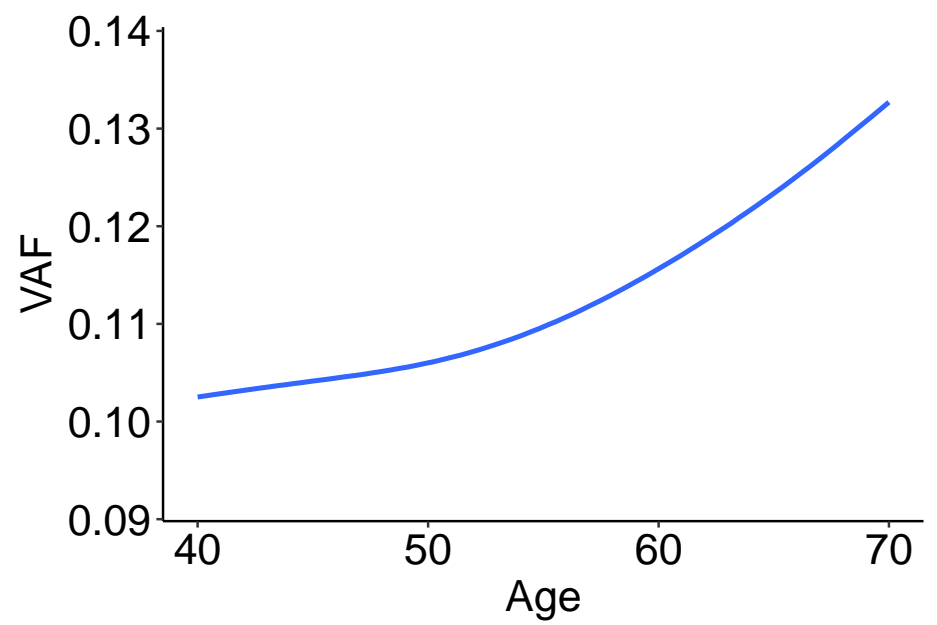

b

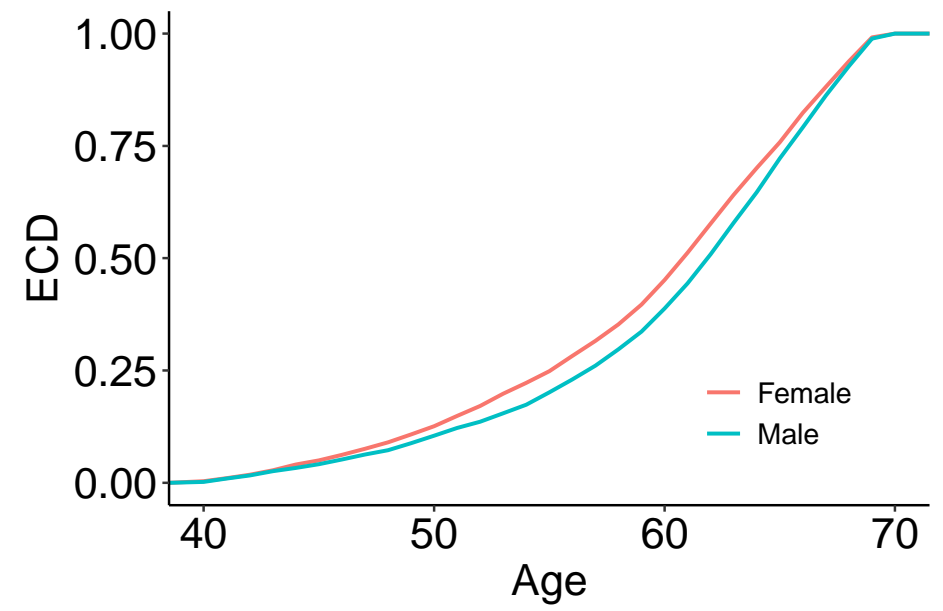

C

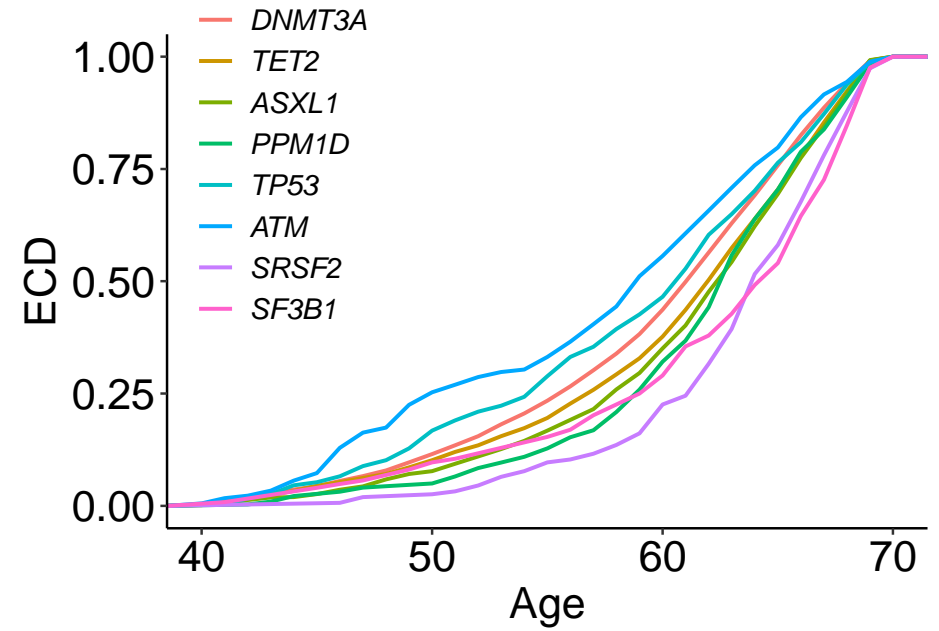

Extended Data Fig. 2: Age-distribution of $\mathrm{CH}$ by clone size, sex, and mutant gene.

a, Clone size, estimated by the variant allele fraction (VAF), increases with age. The blue line represents the smoothed model fitted to a generalized additive model and the shadow represents the $95 \%$ confidence interval. b. Empirical cumulative distribution (ECD) of the age of individuals with $\mathrm{CH}$ stratified by sex. $\mathrm{CH}$ was observed one year earlier in females than in males (median 61 versus 62 years; $P=1.6 \times 10^{-4}$, two-sided pairwise Wilcoxon rank sum test). $\mathrm{c}$, ECD of the age of individuals with $\mathrm{CH}$ stratified by the eight most common driver genes. Compared to DNMT3A, mutations in ATM were observed 3 years earlier $\left(P=7.2 \times 10^{-4}\right)$, while mutations in ASXL1, PPM1D, SRSF2, and SF3B1 and were observed $1\left(P=2.7 \times 10^{-8}\right), 1\left(P=8.5 \times 10^{-6}\right)$, $2\left(P=5.7 \times 10^{-10}\right)$, and $3\left(P=6.5 \times 10^{-6}\right)$ years later, respectively. Differences were calculated using a pairwise Wilcoxon rank sum test. 
medRxiv preprint doi: https://doi.org/10.1101/2022.01.06.22268846; this version posted January 6, 2022. The copyright holder for this preprint (which was not certified by peer review) is the author/funder, who has granted medRxiv a license to display the preprint in perpetuity.

It is made available under a CC-BY-NC-ND 4.0 International license
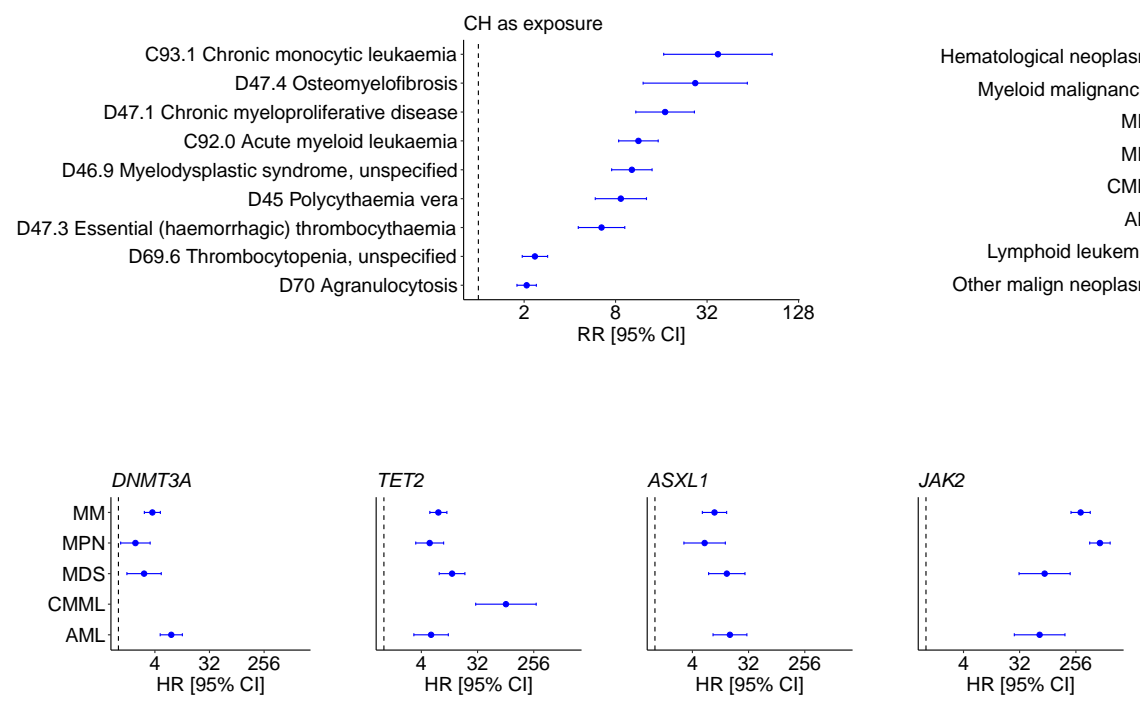

- $\mathrm{CH}$ small $-\mathrm{CH}$ large d

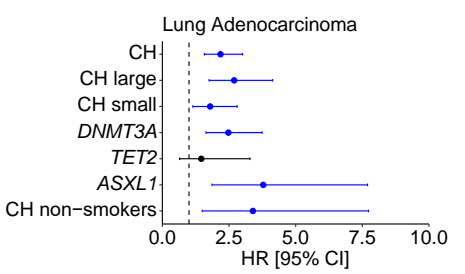

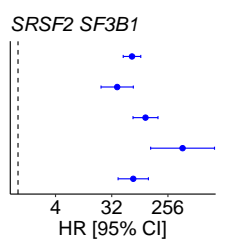
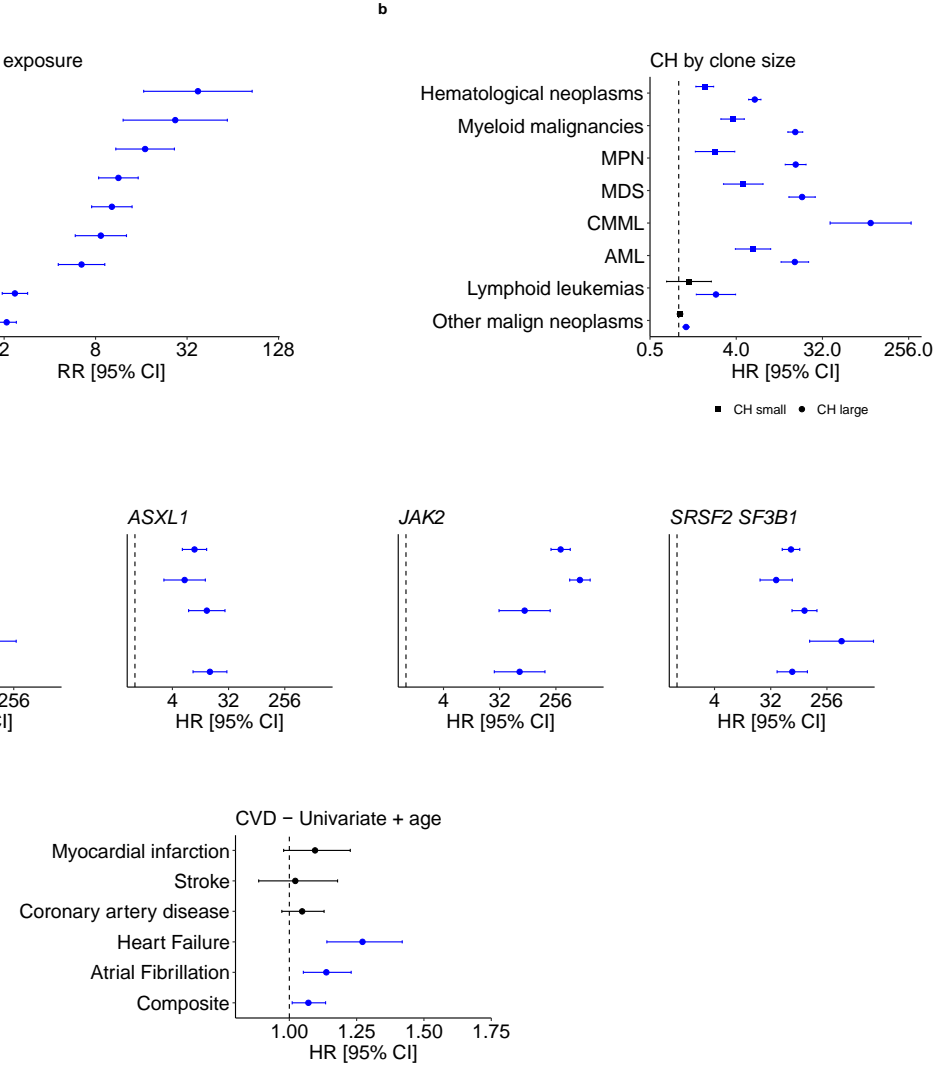

1018 a, Association analysis of $\mathrm{CH}$ with International Classification of Diseases version-10 (ICD-10) disease codes, showing the risk

1019 ratios (RRs) for ICD-10 codes with $\mathrm{CH}$ as exposure. Only ICD-10 codes with false discovery rate (FDR) $<10^{-10}$ are represented.

1020 Error bars represent 95\% confidence intervals (Cls). b-c, Forest plots showing the hazard ratios (HRs) from Cox proportionalhazards models for association with subsequent hematological and other malignant neoplasms for $\mathrm{CH}$ with small and large clones (b) and $\mathrm{CH}$ driven by mutations in specific genes (c). d, Forest plot showing the HRs for subsequent/incident lung adenocarcinoma for overall $\mathrm{CH}, \mathrm{CH}$ with large and small clones, and $\mathrm{CH}$ with DNMT3A, TET2, and ASXL1 mutations, as well as for overall $\mathrm{CH}$ restricting to only self-reported "never-smokers". e, HRs for subsequent/incident cardiovascular disease (CVD) conditions after $\mathrm{CH}$ at baseline using a bivariable model containing age as the only covariate. For b-e, HR markers with $P$-value $<0.05$ are depicted in blue. Error bars represent $95 \% \mathrm{Cls}$. Numerical values for RRs/HRs, $95 \% \mathrm{Cls}$, and $P$-values are reported in Supplementary Tables 9-12. 
medRxiv preprint doi: https://doi.org/10.1101/2022.01.06.22268846; this version posted January 6, 2022. The copyright holder for this preprint (which was not certified by peer review) is the author/funder, who has granted medRxiv a license to display the preprint in It is made available under a CC-BY-NC-ND 4.0 International license.
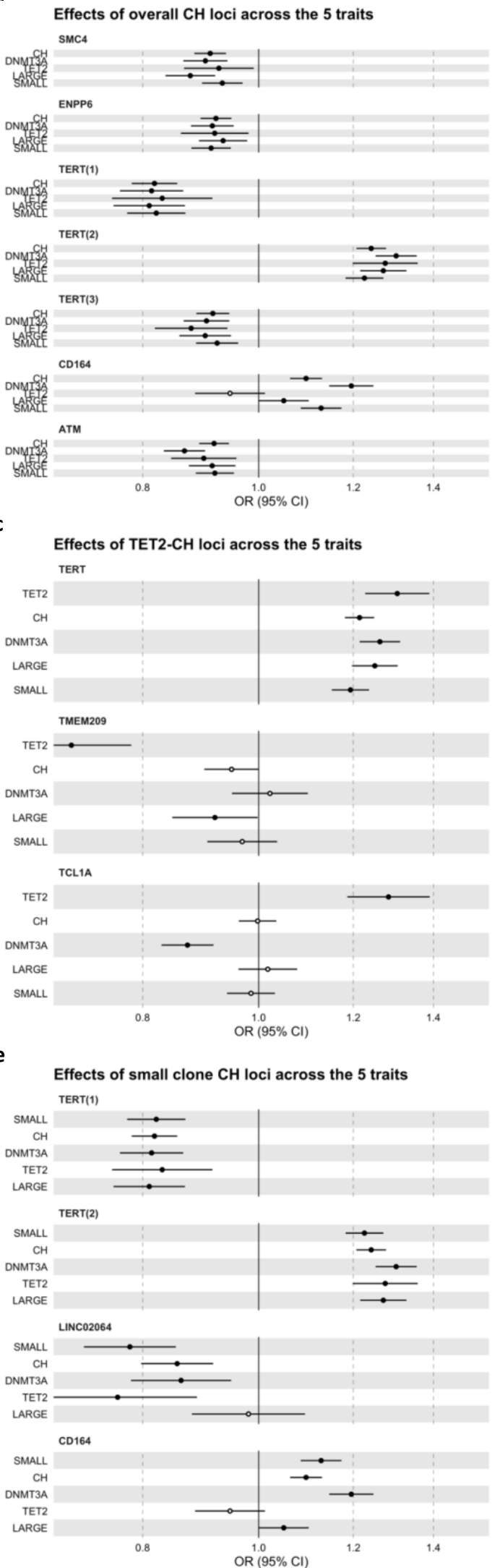

Effects of DNMT3A-CH loci across the 5 traits

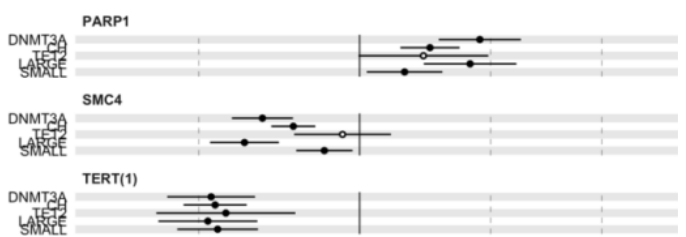

TERT(2)
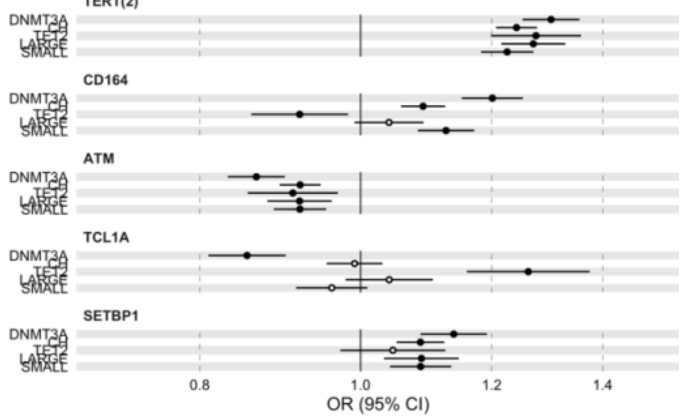

Effects of large clone $\mathrm{CH}$ loci across the 5 traits SMC4

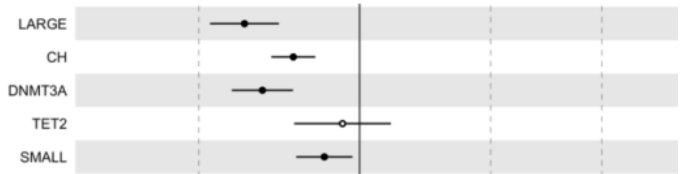

TERT(1)
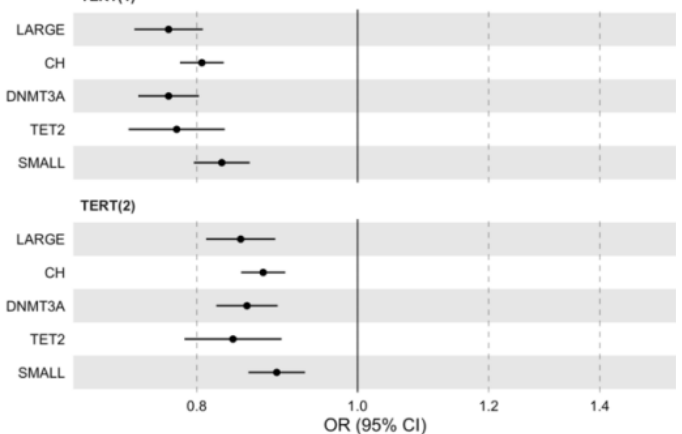

Extended Data Fig. 4: Heterogeneity of lead GWAS variants across five $\mathrm{CH}$ traits.

1030 Forest plots with odds ratios (ORs) and 95\% confidence intervals (Cls) based on data from Supplementary Tables a, 16, b, 18,

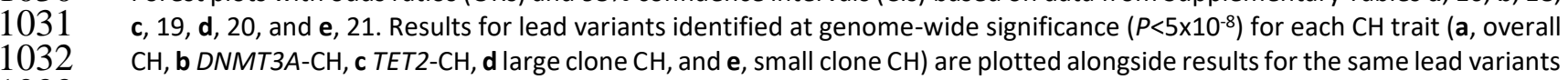

in the four other genome-wide association analyses conducted. 